\title{
THE THYREOID GLAND OF THE TELEOSTS
}

\author{
J. F. GUDER.NATSCH \\ From the Department of Embryology and Experimental Morphology, \\ Cornell University Medical School, New York City
}

TWENTY-ONE TEXT FIGURES AND FIVE PLATES

During the summer of 1909 at the suggestion of Dr. C. R. Stock$\operatorname{ard}^{1}$ I undertook the study of the distribution of thyreoid tissue within the gill region of Teleosts, especially of the trout. It seemed important to clear up certain doubtful facts in this connection, since this organ of the trout is liable to disease and at present is attracting considerable attention in cancer research. The examination of but a small number of species brought such an abundance of interesting material to light that I determined to carry out a comparative study of the anatomy and histology of the thyreoid gland in a large number of Teleosts, and to summarize our entire knowledge of the organ in this group of vertebrates. At the same time I attempted, by comparing the present results with the facts known of the thyreoid in other classes, to define more clearly the features of this organ in the entire vertebrate group.

It gives me pleasure to express my best thanks to The Wistar Institute of Anatomy and to Prof. F. R. Lillie for the use of a room in the Marine Biological Laboratory at Woods Hole, Mass. Some of the species were obtained from the New York Aquarium, for which I wish to thank the Director, Mr. C. H. Townsend.

Twenty families of Teleosts including twenty-nine species were investigated, the detailed description of which I give in the special

${ }^{1}$ My thanks are due to Professor Stockard for many suggestions during the work and for carefully revising this paper.

JOURNAL OF MORPHOLOGY, VOL. 21, NO. 4 SUPPIFMENT: FEBRUARY, 1911 
part of this paper. The results demonstrate the possibility of unusually wide variation in the thyreoid gland and establish a continuous series of transitions from one form to the other.

The general part deals with the anatomy, histology and embryology of the organ, and is based on the facts gained from a systematic comparison of all the species.

\section{GENERAL PART}

\section{ANATOMY OF THE GLAND}

The literature relating to the structure and the location of the thyreoid gland in Teleosts and fishes in general is comparatively meagre. Long after the presence of this interesting organ had been known in the higher vertebrates it was also found in fishes. Simon was the first to demonstrate the existence of a thyreoid gland in this lowest class of vertebrates, but as he supported his statements only by macroscopic examination, it is not certain whether everything he regarded as thyreoid really belongs to this organ.

The peculiar anatomy of the gland renders it at times very difficult, if not entirely impossible, to diagnose tissues in the gill region as thyreoid without a microscopic examination. I have several times, especially when particles of the thyreoid were diffusely scattered, regarded small masses of tissue as thyreoid which under the microscope did not prove to be such. Simon's reports on the different locations of the gland are, therefore, not to be relied upon and it is for the above reason especially that his discoveries in the Gadidae, Cyprinus, Anableps, Esox and Exocoetus are to be very strongly doubted. In these species he locates the thyreoid gland far dorsally in the region of the soft palate. Maurer has since demonstrated the true position of the thyreoid in the carp at least, and although Simon's statements have not been contradicted for the other species, they seem to be, from the phylogenetic point of view, entirely untenable. In some other species, however, Merlangus, Anguilla etc., Simon appears to have found the organ in his dissections, as he places it near the bifurcation 
of the first gill arteries. It seems strange, on the other hand, that he was unable to locate the thyreoid gland in some other fish, among them those in which it is easily visible to the naked eye. Thus he failed to see it in Perca, Mugil, Trigla, Scomber, Tinca, Salmo, (Salmo fario), Clupea, Pleuronectes, Hippoglossus, Rhombus, Solea, Cyclopterus, Gymnotus and Balistes. In all these species, as far as they were at my disposal, I could demonstrate the thyreoid gland as a well developed organ, and feel certain that it is also present in the others. There seems to be little, if any doubt that the thyreoid gland is an organ belonging without exception to all fishes and vertebrates in general.

Of the later investigations describing the thyreoid gland in Teleosts, Baber's work (1881) should be mentioned, although he studied the gland of only one species, the conger eel. A later paper by Maurer (1886) deals principally with the embryology of this organ in the trout, but also contains some remarks on its comparative anatomy.

The thyreoid gland of the vertebrates, as is well known, is closely connected in its development with the median ventral wall of the pharynx and the gill arches. These relationships are only slightly different whether the gills persist throughout life as in the fishes, or are found only in larval stages as in the Amphibia, or finally transform in later embryonic life as is the case in the Amniota. The location of the thyreoid in the animal body is therefore dependent upon the gill region. While in the higher vertebrates the topographical arrangements become more or less changed or rendered indistinct during the progress of development we find them in the fishes typically marked.

The region of distribution of the thyreoid gland in the fish extends below the floor of the pharynx, in the body of the tongue, between the gill arches and back posteriorly behind the origin of the third and fourth branchial arteries from the ventral aorta. Maurer limits the region of distribution anteriorly by the bifurcation of the aorta and posteriorly by the last branchial aortic arch, but these lines are certainly too limited, especially in the anterior direction. In some species the main body lies in front of the aortic bifurcation. The posterior limit, however, only 
exceptionally occurs behind the last branchial arch. The single parts of the basibranchiale define this 'thyreoid region' dorsally, while ventrally the paired musculus sternohyoideus is spread out beneath the organ. This region is at the same time that of the ventral aorta and its branches to each of the gills.

Thus the thyreoid gland is located along the trunk through which the blood for the entire body is pumped from the heart into the respiratory organs. The narrow cleft between the bony parts of the floor of the pharynx dorsally and the muscles ventrally is completely filled with thyreoid tissue except for the space occupied by the large arterial trunks. This region, as we see from the extensive literature on the visceral skeleton and musculature in fish, in the manifold development of its bony (cartilaginous) and muscular parts shows a decided tendency to vary. It is only natural that this tendency should be found in the thyreoid gland also; since it has to accommodate itself to the configuration of the tissues just mentioned, a pronounced adaptability must be of the greatest benefit to it. The property of variation is possessed by the thyreoid gland of the Teleosts to a most striking degree and within the same species rather remarkable differences are found. Twelve weak-fish (Cynoscion) for instance, all differed in the extension and position of their respective thyreoids. Similar conditions were observed in other species. This variability within the species may indicate that in the thyreoid gland we have a very unstable organ, which perhaps in vertebrate phylogeny has not yet acquired its final condition. We know that in the higher classes of vertebrates there is the same variability among individuals regarding the development of their thyreoid glands. In mammalia the individual variation is very great. The lobes may have different forms, and give to the organ a paired appearance, or there may be a more or less well developed isthmus between them. Interesting comparisons have been made especially in man. ${ }^{2}$ In the phylogenetically younger epithelial bodies the variation is still larger. All of these facts indicate that the gill slits and their

\footnotetext{
2 Marshall ('95) examined the thyreoid glands in sixty children in which he found all possible variations.
} 
derivates are still easily modifiable and do not yet represent a permanent condition.

The thyreoid gland of Teleosts is not a single compact organ, as we find it in the higher vertebrates, where the small parts of the gland, the follicles, are united into one complex and enclosed by a common capsule of connective tissue. Only in such a case would the term 'gland' be justified, since here numerous anatomical elements possessing the same physiological function are closely connected. The Teleosts, however, possess numerous elements, whose totality from a physiological standpoint one must regard as a thyreoid gland, while anatomically we are unable sharply to define the organ in question in this group of vertebrates. In most cases we can speak of thyreoid follicles only, or groups of follicles, in pointing out the distribution of the organ. Thus in plates I and II, not the thyreoid glands of the respective species, but the regions of distribution of the thyreoid follicles themselves are figured. On plate III, however, which indicates the variation in the location of the gland within the species, real parts of the thyreoid are indicated, so far as they were macroscopically visible.

In the more closely defined region we may find thyreoid tissue in all parts. It is usually of a brownish yellow color. The follicles are gencrally most densely located in the neighborhood of the ventral aorta or of the branchial arteries. Those places, particularly, are favored where the branchial arches arise from the aortic stem. Follicles are most abundant at the origin of the second gill arteries, that of the first being next, and finally the roots of the last branches have fewest thyreoid follicles about them. A more or less dense accumulation is always found along the stem of the ventral aorta, which may be completely surrounded by thyreoid tissue. In other cases dense accumulations of follicles are located either dorsally or ventrally to the aorta.

The glandular tissue is usually distributed so that it is more densely accumulated in the central region, while towards the periphery a more and more pronounced dissolution and scattering of the follicles takes place. These conditions cannot, however, be strictly generalized, as we find cases in which, even in the most central portions, the follicles are not more closely arranged than 
in the peripheral. In some instances, as in Cynoscion, rather well developed central portions are found which can be recognized by the naked eye. But even in these cases numerous follicles lie well separated from the main body. Thus we have all transitional stages from a perfect dispersion of the follicles to a rather compact union of them. It is possible that further investigations may show cases in which the organ is still more compact than in those thus far examined, and so present a structure similar to that in higher vertebrates. Judging from my observations, however, this does not seem probable, and at present I am inclined to regard the conditions found in Sarda (vide Special Part) as the limit of compactness in the series.

The cephalad and caudad extensions of the thyreoid gland vary very much. In general, it might be said that a spreading out toward the tip of the tongue takes place in all cases, while towards the heart the distribution is not so uniform. Far cephalad of the first aortic bifurcation we find single follicles scattered below the hyoid bones. The caudal limit of the thyreoid gland usually lies between the second and third aortic branches, or at the third. Rarely does it go beyond this point, and if so, with a few exceptions, only scattered follicles are found in the posterior region. Thus we find an accumulation of the glandular elements around the anterior part of the ventral aorta, with follicles scattered towards the head and the heart.

The organ decreases in mass in an anterior-posterior direction. In one instance, Siphostoma, just the reverse is the case.

The embryonic center from which the thyreoid starts to grow lies between the first and second gill branches, this place in the adult animal is near the aortic bifurcation, and in many cases we find the main part of the organ in this region; while in other cases, Cynoscion and Tautogolabrus, it is exclusively there. From the region of the aortic bifurcation the thyreoid elements travel so as to occupy the different positions which are described in the special part of this paper. The migration of thyreoid follicles occurs more particularly in the direction of the heart, although a cephalad migration is decidedly pronounced. The development of the hyoid bones obstructs the anterior spreading 
of the follicles to some extent. The follicles apparently tend to go around the basihyale and along its sides towards the tip of the tongue. In the dogfish and shark where the hyoid region offers a comparatively free space we find it occupied by the compact thyreoid, which is pushed slightly forward of the aortic bifurcation (Ferguson). In these animals also the thyreoid is originally placed in the bifurcation of the truncus; later, according to W. Müller, the anlage moves forward and becomes encapsuled. In Raja, on the other hand, it remains in the bifurcation.

The dorso-ventral, in combination with the lateral, extension of the thyreoid follicles seems to be more dependent upon the configuration of the pharyngeal floor than does the cephalo-caudad extension. In fishes, in which the isthmus region is deep and narrow, as in Brevoortia, we find, as might be expected, the dorsoventral distribution of follicles far surpassing the lateral. While in other species, for instance, Tautoga, in which the floor of the pharynx is very broad, the lateral extension is the important one. In general it may be said that the lateral outweighs the dorsoventral distribution of follicles.

Dorsally the follicles are usually found between the ventral aorta and the copulae of the gill arches. In cases where those skeletal parts come close to the vessel the follicles are forced away laterally, and sometimes intrude into the spaces between the copulae and hypobranchialia. When the parts of the basibranchiale lie well separated the follicles extend up between the copulae and come to lie close to the mucous membrane of the pharyngeal floor.

The main mass of the organ lies almost exclusively above, or dorsal, to the ventral aorta. This is opposed to Maurer's statement of the case. Below the aorta is usually found the smaller part of the gland and the follicles are also more loosely scattered. The development of the thyreoid gland above the aorta should be expected since there is usually much more open space between the aorta and the gill arches than is found below the aorta where the muscles lie close to the vessels. The thyreoid elements endeavor to intrude below the aorta as much as possible, and when this vessel, in the region of the third branchial arteries, sinks deeper 
into the musculus sternohyoideus, the follicles follow in the course and are thus distributed far ventrally within the muscle. The number of follicles along the sides of the aorta is always less than either above or below it. This by no means contradicts the statement made above that the lateral exiension of follicles outweighs the dorso-ventral one. Only in the genus Fundulus, especially in majalis, Iess so in heteroclitus, where a transverse interbranchial muscle pushes the vessels away from the skeletal parts, is the dorsal extension small, or sometimes lacking entirely. Here the follicles extend directly away from the aorta towards the bases of the gills.

Along the aortic stem between the bases of the gill arteries the lateral extension is somewhat limited and reaches its height along the branchial arteries. The vessels seem to serve as bases along which the follicles migrate. The free space about the gill arteries becomes narrower and narrower as the gill arches are approached and therefore the number and size of the follicles decrease towards these points until there is no more room for extension. When, however, there exists an especially open passage along the vessels the follicles may even extend into the gill arches, to a considerable distance beyond the point of their origin. Such cases are common in trout (text fig. $7 D$ ).

The peculiar distribution of the thyreoid elements forces us to regard the organ in bony fishes as unpaired, a view also supported by embryology. This statement should be especially emphasized, as in Wiedersheim's Comparative Anatomy, 1907, the author still speaks of the thyreoid gland in the Teleosts as a paired organ, although Maurer in 1886 (p. 134) criticizes this statement in an earlier edition. On another page, (p. 140) Maurer himself claims that the main bulk of the organ at a certain stage is not paired, while later single portions of the gland lying in the median line, as well as on both sides of the truncus arteriosus, take a paired arrangement. This is certainly incorrect, since the follicle groups on the sides of the aorta are not only unpaired but are also not bilaterally arranged.

The relationship between the thyreoid gland and the stem of the ventral aorta is purely anatomical and without any physiological 
importance. The thyreoid does not receive its blood supply from this group of vessels, since they carry only venous blood, and the arterial blood which nourishes the gland comes from a special thyreoid artery. In Petromyzon, however, Cori claims that the arteria thyreoidea arises from the truncus arteriosus; this is probably an error, as he also finds the ventral carotid connected with the truncus. The thyreoid artery, as Silvester demonstrated in Lopholatilus and twenty other species of Teleosts by his perfected method of injection, arises as a dorsal branch from the united right and left fourth commissural arteries. The latter vessels originate from the second efferent branchial arteries and unite in the median line below the thyreoid and the aorta as the hypobranchial artery. Shortly after the union of the fourth commissural arteries the thyreoid artery branches off from the dorsal side and immediately enters the gland in its posterior region. Whether the widely scattered follicles all receive their capillaries from this one vessel cannot at present be stated, though it would seem very doubtful especially in the case of the more anteriorly isolated follicles.

In Selachians, where the thyreoid is pushed far forward, the arteria thyreo-spiracularis (Dohrn) originates in the first aortic arch from the arteriae efferentes of the hyoid gill. In Teleosts, also, the first aortic arch breaks up into a capillary network. Dohrn, therefore, speaks of an arteria thyreo-spiracularis. Perhaps it is from this vessel that the most cephalad parts of the thyreoid gland receive their blood supply. The artery pointed out by Silvester seems, however, to supply the bulk of the organ, and the term arteria thyreoidea as applied to it is apparently justified.

It is of interest to recall Simon's statement, which was also supported by others, that the thyreoid gland is placed in the blood system so as to regulate the supply of blood to the brain. This, in a way, was a foreshadowing of our present views that the physiological action of the thyreoid gland exerts an important influence on the central nervous system.

The venous blood from the thyreoid gland passes into the thyreoid vein, a vessel, which also collects the veins from the muscula- 
ture below the aorta and carries the blood directly into the sinus venosus.

Little is known about the relation of the thyreoid gland to the lymph system. This is largely due to the fact that in the fishes the lymph vessels are in a much closer connection with the venous system than in the higher vertebrates. It is almost impossible to distinguish between veins and lymphatics by the injection method.

In many species large cavities lie around the aorta, two dorsal ones being constant in trout. These are extraordinarily large and lined with endothelium and although they often contain blood corpuscles there is little doubt that they are lymph sinuses. The corpuscles probably come in from the venous system, or possibly by traumatic haemorrhages. A further fact in favor of their being lymph sinuses is that no descriptions of large veins in this region has come from the numerous injections of the circulatory system of Teleosts. In some species there is only one large 'lymph sinus' which surrounds the aorta dorsally and laterally.

\section{DEVELOPMENT OF THE THYREOID}

Only one contribution deals with the embryology of the thyreoid in Teleosts, this is by Maurer ('86) who traces its development in the brcok trout. The gland arises in much the same manner as it does in the other classes of vertebrates.

The thyreoid develops very early in the Teleosts, after the first gill slit has broken through, ${ }^{3}$ as an unpaired evagination of the stratified epithelium on the ventral side of the pharynx between the first and second gill pockets. It is thus placed in the curve of the S-like tubular heart before the gill arteries have developed, with the exception of that to the hyoid arch. The vesicular thyreoid anlage very soon separates itself from the pharynx and enlarges by budding. The organ lies close to the tubular heart, but only remains for a short time near the place of its origin. With the development

\footnotetext{
${ }^{3}$ In Hertwig's Handbuch d. Entwicklungslehre II, 1, 1906, Maurer states, however, that the anlage of the thyreoid appears in all Gnathostoma before the breaking through of the first gill slits.
} 
and shifting of the heart and aorta as well as by its own growth the thyreoid gland comes to lie far from its original position. The absence of a capsule of connective tissue similar to that in higher vertebrates admits the loosening and separation of the thyreoid follicles in the bony-fish. ${ }^{4}$

The Teleosts show a condition of the thyreoid gland somewhat similar to that in Myxine glutinosa, as W. Müller, Cole, Schaeffer and Maurerstate. The follicles in Myxine, partly isolated, partly in groups, are found between the pharynx and the truncus arteriosus throughout the gill region. In the Teleosts, however, the gland also extends below the truncus. In the skate Baber observes "a single body and a few detached vesicles"; in the Amphibians separated particles have also been described. Yet in both of these groups the thyreoid possesses a capsule, which sends septa into the inner portions, as W. Müller has shown for Acanthias and Raja. Maurer finds a delicate connective tissue capsule in the Urodela. These observations on Selachii and Amphibia, however, are exceptional and the small detached particles can only be looked upon as 'aberrant thyreoids' the main thyreoid in all cases being a sharply defined body. Maurer observed in the Urodela that a breaking up of the thyreoid into smallerparts occasionally occurred. These accessory thyreoid glands were parts of the former isthmus which, after the anlage had divided, persisted and remained in their original position, while the true halves moved in a postero-ventral direction. In the Ophidia the organ is compact and encapsuled; but in the Saurii, according to W. Müller, the interstitial tissue increases so much through the accumulation of fat, that the glandular tissue proper is broken up into irregular groups which are sometimes completely disconnected. We have here a dissolution within the capsule suggesting that the connective tissue capsule is the only factor in other vertebrates which prevents the thyreoid elements from becoming scattered about as they are in Myxinoids and Teleosts.

\footnotetext{
4 The elements of the Teleost pancreas are similarly scattered in the mesenterium.
} 
During development of the Teleosts some follicles cling to the wall of the aorta and are in later life found along it. Usually the follicles become arranged into several distinct groups, forming different centers of growth, as is shown by Cynoscion in plate III. With the branching off of the gill arteries from the aorta thyreoid material is carried out laterally towards the gil's and spreads in this region. This accounts for the larger lateral extension of thyreoid follicles along the gill vessels rather than in intermediate regions. The larger vessels form a substratum upon which the follicles migrate as do also the smaller vessels and especially the lymphatic vessels. The larger vessels are means for the antero-posterior dispersion while the smaller ones allow the migration of follicles from the denser central thyreoid portions towards the periphery. Even the most peripheral follicles are usually found near blood capillaries although they do not necessarily come in close contact with them. The way in which these isolated follicles function is not clear. They certainly seem normal and contain colloid.

The growth of the connective tissue and fat in which the follicles are imbedded favors their dispersion from the central portions; thus a combination of influences are at work to widen the thyreoid region as much as possible. $W$. Müller regards the immense development of the 'interstitial' tissue as alone responsible for the dissolution of the thyreoid into isolated groups. He no doubt refers to fat and connective tissue, as we shall see below that the term 'interstitial' is not properly used in this case. Although the growth of these tissues may be an important factor I do not regard it as primary, since in the first place, even in young individuals, the follicles are found isolated, and secondly, the breaking apart of a formerly compact organ by excessive growth of connective tissue would certainly not account for the carrying of the follicles into the muscles and gills.

The follicles actually seem to overcome the obstruction offered by other tissues in their course and may even penetrate into them. In trout and Micropogon the thyreoid follicles are at times imbedded in the muscle tissue, into which they creep betwcen the connective tissue lamellae or along the blood vessels. Real activ- 
ity on the part of the follicles is most unlikely, and the probability is that they are simply passively pushed or pulled as circumstances may have it. The forces in development unite to make it possible for the thyreoid gland to spread, and so form a greater amount of functional tissue than could be contained in a compact organ situated in the narrow space between the basihyale and the ventral musculature.

Little is known of the manner in which the thyreoid gland grows and forms new follicles, and contradictory statements are also found in the literature regarding the primary anlage of the organ. It is scarcely conceivable that a vesicular anlage should exist in all fishes except Ceratodus in which Greil observed a solid one. Before the solid outpushing in Ceratodus separates from the pharyngeal wall it is said to become vesicular, a process exactly the contrary to the usual one.

tmphibians are believed to have a solid bud-like thyreoid anlage. Maurer states that two days after its evagination the thyreoid is solid in the Anura, and W. Müller observed a solid anlage in Rana temporaria and platyrrhinus, in which the first lumen appeared in $25 \mathrm{~mm}$. larvae, after the gland had divided into two halves. In the Urodela Maurer records a solid epithelial bud, Livini finds the same in Salamandrina perspicillata and Muthmann in Triton alpestris. Platt claims that Maurer's description does not apply in all the Urodela, as is shown by the condition in Necturus.

The reptiles, birds and mammals are said by the majority of observers to show a vesicular thyreoid anlage, which changes into a compact organ from which follicles later originate. Kölliker, however, observed in the rabbit a thickening in the ventral wall of the pharynx, from which a wart-like solid process was cut off. Born also records the same for the pig. (Both authors quoted from Streckeisen).

This point is of importance in phylogenetic interpretations since our present views regarding the ancestry of the thyreoid gland are mainly based on a similar evagination, that for the endostyle, found in the Tunicates and Amphioxus. 
Maurer finds in the trout a primarily globular vesicle stretching in an antero-posterior direction, and on the 41st day of development lying ventral to the stem of the aorta. If these statements apply to all Teleosts, the thyreoid must first originate dorsal to the aorta and early migrate ventrally and later return to a position dorsal to the vessel, since it usually occurs there in the adult. The condition in the Teleosts is similar to that in the Myxinoids, where Stockard describes the origin of the thyreoid as a median down-pushing from the ventral floor of the pharynx throughout the entire gill area, and consisting, in newly hatched Bdellostoma, of diffusely scattered alveoli below the pharynx and above the median branchial artery (ventral aorta).

In the trout, where development is rather slow, Maurer observes that 35 days after fertilization, when the embryo is about $6 \mathrm{~mm}$. long the first thyreoid vesicle begins to pinch away from the pharynx. While originally the evagination, visible on the 28th day, possesses a stratified epithelium, it has on the 35th day a single layer of cuboidal cells. Three weeks later the whole stem of the aorta is surrounded by follicles. I find in rainbow-trout, one month old, or only 30 days older than those mentioned by Maurer, that the majority of follicles, and the larger ones, lie above the aorta.

Maurer also observes that in the brook-trout shortly after the first follicles have appeared the organ grows so rapidly that for a considerable period it surrounds the aorta as a compact mass. "In very late embryos, the growth of the thyreoid does not keep pace with that of the artery; thus the gland breaks away from the aorta and separates into a number of irregular clusters of different sizes lying either laterally partly paired or dorsal or ventral to the aorta, always, however, in its immediateneighborhood." He records the main mass of the gland in trout of even $25 \mathrm{~cm}$. as being compact and situated ventrally between the second and third branchial arteries, and it is only in animals of $30-40 \mathrm{~cm}$. that the thyreoid breaks up into the clusters of follicles characteristic of the adult. Maurer describes the same conditions in a number of other species, of which only the eel was at my disposal. The age of the eel I examined was unknown, though 
according to Maurer it must have been rather old, yet it measured only $30 \mathrm{~cm}$. long.

Maurer's observations do not accord with the conditions I find in rainbow-trout four weeks old, nor in $25-30 \mathrm{~cm}$. brook trout. As before stated, there is no paired arrangement of the thyreoid clusters, and the follicles are also in many cases distantly removed from the stem of the aorta. Other differences may be either due to specific or individual variations. Maurer's statements would indicate that the thyreoid gland tends to preserve its original unity, being finally broken up by force. My observation, however, seems to show the contrary, at least in Salmo irideus and fontinalis. In individuals one year old the follicles are more densely packed than in those one month old, although the intervening spaces have grown larger. The follicles also have become more numerous. This seems to warrant the supposition, that the thyreoid elements are disassociated at an early stage and subsequently multiply.

The multiplication of the follicles is described by Maurer as being very simple. While the epithelial cells are increasing in number after the forty-first day (in trout) solid buds appear on the primary vesicle, which very soon form central cavities and then pinch away. We do not know whether a similar process is maintained in later life, follicles coming from follicles, or whether new follicles are derived only from primary epithelial cells multiplying and forming a lumen. The latter supposition would more readily explain the scattering of thyreoid elements, germ elements I might say, to distant regions. L. Müller believes the new follicles to originate from old ones by buds from the epithelium which are subsequently pinched off. Baber contributes an interesting observation in the conger eel where in the wall of large follicles small ones sometimes lie imbedded so deeply that the epitholium between them is flattened out. Baber thinks that at times the wall breaks through and the two lumina are united. In other cases, however, the small imbedded follicles grow out and become independent.

The epithelial tubes found in the thyreoid of higher vertebrates as transitory growth stages are absent in the Teleosts. In the 
Urodela a solid cylinder of epithelial cells from which the follicles pinch away, exists for from two to four weeks. These cylinders are observed in sheep and pig embryos up to the $20 \mathrm{~cm}$. embryos and in man up to the $24 \mathrm{~cm}$. embryo. The follicles in fish are formed comparatively earlier, and perhaps the gland functions earlier.

Thus a rapid multiplication of follicles occurs in the Teleosts without the formation of cell cylinders. This is an exception to W. Müller's claim that the thyreoid gland in all vertebrates passes through three stages: (1) a severing of the anlage from the pharynx; (2) formation of a network of tubes of glandular epithelium; and (3) the formation of follicles from these tubes. In the Teleosts and also in the Myxinoids, as Stockard has shown for Bdellostoma, the second stage seems to be suppressed or absent.

The first appearance of colloid in the thyreoid gland is generally thought to occur early in lower vertebrates but very late in the higher ones, towards the end of fetal life or often not until extrauterine life.

Maurer reports colloid in the trout thyreoid on the forty-first day of embryonic development. How far this early appearance of colloid is connected with the function of the organ is unknown. From a comparative physiological standpoint it would seem that in the lower forms the thyreoid might function much earlier than in the Placentalia, where in intra-uterine life the gland of the mother might supply the needs of the developing embryo. ${ }^{5}$

\section{HISTOLOGY OF THE GLAND}

The histological structure of the thyreoid gland in Teleosts has been little studied. The meagre observations made by Baber in 1881 , describing some features of the thyreoid in the conger eel were the first reported. Maurer later ('86) mentions a few points regarding the histology of the thyreoid in the trout and carp.

The microscopic appearance of the gland varies as much as does its anatomical structure. In sections from some specimens the

- In young mammalian embryos Peremeschko found no colloid, in older embryos it occasionally existed, while in young animals colloid was present in the majority of follicles and in old ones in all of them. 
follicles are closely arranged and so densely packed that apparently only lymph spaces exist between them, in others we find the follicles more loosely connected and suspended in the connective tissue; while again in other specimens they lie so far apart that they can scarcely be thought of as belonging to one organ. The histological appearances also differ very much within the individual, depending upon the region from which the section is taken.

When the arrangement is such that the thyreoid may be dissected out and then sectioned, the follicles are found to be rather densely packed (pl. V, fig. 17). By this method, however, we are unable to get a correct idea of the extension of the thyreoid and the arrangement of its follicles, since it is only possible to remove the somewhat denser masses around the stem of the aorta, usually near the base of the second aortic arch, and all the particles in front and behind this region still remain. Properly to study the general distribution of the thyreoid follicles serial sections through the entire gill region are absolutely essential.

The spaces between the muscles, branchial arteries and gill arches are filled by wide-meshed connective and fatty tissue. In these tissues the follicles are suspended. The connective tissue is, therefore, not so directly a part of the thyreoid organ in these fish as it is in the encapsuled organ of mammals. The primary object of this tissue is to form a connection between the muscles and bones without regard to whether there may be thyreoid tissue in the region or not. True interstitial tissue, as such, is not found in this diffusely scattered thyreoid organ. Of course, the tissue in which the follicles lie imbedded performs the same function as does the capsule in higher vertebrates: in both cases it serves to support the follicles. In glands, where many follicles are accumulated in one mass, as in Cynoscion, or in the central portions of some others, for instance the trout, the supporting tissue may be regarded as part of those masses, but not as part of the entire thyreoid gland; here also the formation of connective tissue is the primary process, and the suspending of the follicles only a secondary one.

The supporting tissue is simple except in two species, Salvelinus and Sarda (pl. V, fig. 21) where smooth muscle fibres are freely 
suspended in the connective tissue. These muscle fibres are found especially below the aorta, where they approach the follicles and at times surround them. This is accomplished by the fibrillae of a bundle loosening up a little, then enclosing a row of follicles and finally uniting again. ${ }^{6}$

Regarding the number, size and form of the follicles, all variations exist which have been demonstrated by comparative investigations in the other classes of vertebrates. The size of the follicles is, in general, in reverse proportion to their number. The size, however, is not of great importance, since the chief factor in the activity of the gland is the epithelial surface; this will be the larger, the greater the number of small follicles contained in a given region. Biometric calculations would be interesting in this direction as experiments have shown that the functional value of the thyreoid gland varies with the individual. Glands are found in which the size of the follicles is uniform; in such cases the follicles are usually large. As a rule, however, the follicles are of various sizes as would be expected in view of the process of formation of new follicles. In many cases I have observed that a few (three or four) follicles are unusually large.

The follicles lying in the central parts are generally larger than those towards the periphery. This seems quite natural in view of the mode of extension of the gland. In only one case, Sarda, do the central portions consist of nests of numerous small follicles while larger follicles lie peripherally (text fig. 12). This condition resembles somewhat that in birds (Baber), and mammals (Anderson, Forsyth) and if it be due to the fact that in Sarda the gland is almost as compact (of course without a capsule) as in the higher vertebrates (with capsule) then we must suppose that in such a case new follicles are formed in the centre and are pressed out towards the periphery, while in the breaking up of the gland minute parts are continually carried towards the periphery and there form new follicles. In the first case the peripheral follicles would be the oldest and in the second the youngest ones.

\footnotetext{
- Streiff finds muscles between the glandular tissue in the thyreoid of the cat, Zielinska in a young dog, Wölffler in a child (cit. from L. Müller), L. Müller in an adult woman. The muscle must have migrated into the gland during the first half of the embryonic period, before the capsule was formed.
} 
The form of the follicles is also variable, most typical perhaps are the globular or elliptical and tubular types. The smaller follicles are nearly always circular in section (pl. V, figs. 10-12), especially when they are free. The shape of the more closely packed follicles is influenced by pressure, and may be flat, indented, or irregular in outline. When the follicles lie next to the cartilages or muscles they are usually oblong-oval, with the longer side towards the tissue. Single follicles lying in the supporting tissue, if large, are rarely prefectly circular, but have irregular outlines due to pressure from the fibres of the substratum. The shape of these follicles indicates the existence of actual pulling forces in the supporting tissue.

Not only small irregularities are found in the surface of the follicles, but also deep invaginations of the epithelium as well as long evaginations. The follicle may consist of a central body with sprouts or branches of cylindrical and globular shapes ( $\mathrm{pl}$. $\mathrm{V}$, figs. 15, 16). How far these irregularities in form are connected with the cutting off of smaller follicles from larger ones could not be determined. Anderson doubts the multiplication of follicles by such a process.

It is now generally accepted that no communication from follicle to follicle exists; the follicles are closed on all sides and perfectly separated from each other. Sometimes, however, as many as five follicles are observed in a section, apparently perfectly separated, but on tracing through the series of sections they all unite into one follicle (pl. V, fig. 16). This is due to evaginations from the follicular wall somewhat like the fingers of a glove, which when cut across, give the appearance of several independent follicles, while in reality there is only one lumen. In Anguilla chrysopa, however, there really seemed to be a communicating duct between two follicles; the lumen of the tube was much narrower than that of the follicles and the epithelial cells of it were much higher (pl. V, fig. 15). This closely resembles a 'Schaltstück' as seen in other glands. This was not due to a waist-like constriction of the epithelium, but to a far reaching evagination from one follicle with a globular swelling on the free end representing a second follicle. There was no colloidal substance in the 'intercalary' duct. 
Branched follicles are particularly abundant in some species. In Muraenoides all follicles seem to branch. Baber states that in young animals the follicles are much more ramified than in older ones; he, therefore, regards this branching as the method of follicle multiplication. Anderson, on the other hand, holds the 'melting' of the epithelium (a process about which I shall speak later) at the point where two follicles meet responsible for the communication between several lumina; this of course is an opposite process from that of budding. Anderson, therefore, believes that in old animals there are more irregular follicles than in the young. It seems to me that the ramification of the folliclesdoes not depend so largely upon age, but rather on the species.

The follicular epithelium varies but little with the species, perhaps the number of cells may differ in follicles of the same capacity. The epithelium is of the form usually found in the thyreoid glands of higher vertebrates. All transitions exist from a pavement epithelium of very low broad cells, through cuboidal cells as high as broad, to very high and narrow cylindrical cells (pl. V, fig. 10).

The form of the epithelium is probably connected with the age of the specimen, as it undoubtedly flattens with increasing age. (In very old human subjects only perfectly flat cells have been found.) Age, however, can scarcely be the only factor, as in some species different forms of epithelium appear at the same time. This may be due to the different ages of the follicles, though it cannot be regarded as an absolute rule that the older follicles have a lower epithelium than the younger. Hürthle definitely states that these two factors are independent of one another. Langendorff points out that the follicles increase in size, not by a flattening out of the epithelium, but by multiplication of cells. I should say that both processes may be simultaneously involved since we often find large follicles with high epithelium, yet karyokinesis is rarely observed in the epithelial cells. The latter fact led Stockard to suppose that amitotic cell division might occur in the growing thyreoid tissue of Bdellostoma.

The different types of epithelium might be accounted for in still another way by supposing the follicles to be in different 
stages of activity. Here again we meet with difficulties since the same follicle sometimes shows high cylindrical epithelium on one side and a flattened epithelium on the other (pl. V, fig. 11). Hürthle considers the flattening and stretching of the cells to be the final stage in the process of colloid formation. He finds this type of cells not sporadically, but always in the larger groups of follicles. The low epithelial cells are still alive and accordirg to Hürthle may again transform into high ones. Biondi claims that when the follicle has reached a certain size, the epitheliumpartially flattens and vanishes, thus establishing a communication between the follicular lumen and the lymph spaces and allowing the colloidal material to be poured into the lymph system. The emptied follicle is said to collapse and from its cell mass a new follicle originates. Anderson, also, thinks that by a 'melting' of the epithelium a connection is formed between the lymph space and follicle, but the individual follicle is not destroyed.

In the conger eel Baber finds oval cells between the cylindrical ones and attributes to them the formation of new follicles, an idea which I think is incorrect. The two classes of cells could not be found in the common eel. Baber also finds in the conger eel 'club-shaped' cells between the epithelial cells. They are much narrower than other cells and possess elongated nuclei. Their free ends project above the general surface and are expanded 'fan-like;' the bases may also show a similar condition. Baber regards them as branched cells, often existing in pairs, and forming stomata which play an important part in absorption and secretion. If this be true such cells should exist in all glands. I was unable to find these and think perhaps they may have been consequences of his alcohol preservation.

The form of the nucleus changes with the form of the epithelial cell. It is usually circular or somewhat oval in cross section. When the cell is either cylindrical or flattened, the nucleus becomes more and more elliptical in shape, with its long axis parallel to that of the cell. Thus in the first case the long axis of the nucleus is vertical to the free surface of the cell and in the second parallel with it. When the nuclei are oblong in spite of the cells being broad and cubical (for instance in some follicles of Muraneoides) 
they always present the long side to the free cell surface. Frequently narrow cells with oblong nuclei are seen between the cuboidal cells.

In trout degenerating epithelial cells of small size were observed with compact nuclei, deeply staining or pyknotic.

The nucleus usually lies at the base of the cell (pl. V, fig. 11) but may sometimes, especially in an epithelium with many cells, move a little towards the lumen (pl. V, fig. 10). Nuclei may lie at different altitudes, in an alternating fashion. One or two nucleoli are visible.

The shapes of the nuclei usually give no indication of the state of activity of the cell as Anderson has claimed. Even pyknotic nuclei usually have regular outlines. An exception to this is seen in the trout where often, in some varieties almost exclusively, epithelial cells show nuclei of very irregular shapes, as indicated in pl. V, fig. 10. The nuclei are elongated with more or less bent corners-horse-shoe shape. These were generally found in lower cells; they may have been degenerating, since they did not stain as deeply as the normal ones in other parts of the gland, when such were present. It seems, however, scarcely conceivable that the epithelium of the entire gland should degenerate, unless from some pathological condition. (These animals were all reared in the N. Y. Aquarium.)

The cytoplasm of the cell appears granular and sometimes stains slightly darker in the basal region. There is no cuticle lining the lumen, but the refraction of light in this region has misled some authors. The base of the cells is usually rather smooth, though in cases where vessels come into close contact with the follicle the straight basal line becomes somewhat interrupted through the influence of the surrounding structures. In Brevoortia the epithelial cells are nearly all drawn out as if they possess projections. Those of one follicle approach very closely those of others and it seems almost as if a connection between the follicles were established (pl. IV, fig. 1,2). Other somewhat broader cells possess pedicel-like bases which are sometimes branched, giving the impression that the cells are sending out pseudopodia. The processes disappear in the interfollicular tissue in close contact 
with the blood and lymph capillaries. The process cells are limited in number and lie close together. Their cell body is swollen with foamy cytoplasm containing several deeply stained highly refractive granules. Perhaps these cells are in a state of degeneration, probably colloidization, although their plasma does not show any acidophilia (pl. IV, fig. 5, E). Peremeschko observes somewhat comparable features in the thyreoid glands of birds and mammals, especially in that of the rabbit. Some of the epithelial cells possess at their basal end from one to ten small projections, and thus resemble the tassel cells Pflüger has described in salivary glands, except that in the thyreoids the processes are shorter. In some cases Peremeschko found such cells in fresh material and could isolate these follicles, which appear to be surrounded by a fringe. Pflüger regarded the cell processes as nervous, but Peremeschko correctly believes them to come from the cytoplasm of the epithelial cells.

The function of the follicles can be much more easily studied in other groups of vertebrates than the teleosts. In dissecting out the follicles, as far as they are macroscopically visible, and fixing them, it is almost impossible to avoid destroying the finer structures. Hemorrhages are almost unavoidable in cutting open the gill region. On the other hand, in fixing the entire floor of the pharynx the fixation fluid does not penetrate sufficiently fast to preserve the finest details, and the general structures are unfavorably influenced by the decalcification process. Microchemically, therefore, little can be done and I limit myself to what could be determined from studies of general structures.

Hürthle's colloid cells were seldom seen in the thousands of follicles observed. Whether they are not generally formed, or whether they appear and are emptied in so short a time as to be rarely preserved I am unable to say. In Clupea (pl. V, fig. 20, Coz.) they were limited to four or five neighboring follicles and in these all of the epithelial cells were so swollen that in some cases they met in the center of the follicle, obliterating the lumen. The nuclei were compact and deeply staining and occurred directly under the free surface of the cell. The cytoplasm was homogeneous, highly eosinophile, and sharply distinguished from that of other 
epithelial cells, and thus the colloid forming zone was well defined. This agrees with Hürthle's account, which states that the colloid cells always appear at the same time in a large portion of the wall of a follicle or in several neighboring follicles. The size of the follicles has nothing to do with their appearance. In one case, Siphostoma, the epithelium of all follicles consisted of cuboidal swollen cells, the nuclei of which were near the cell center or towards the lumen and the cytoplasm was highly acidophile, (pl. IV, fig. 8).

The normal contents of the follicles is the colloid. It is found in all thyreoids and usually all the follicles contain it; only in a few cases were the majority of them empty.

In spite of the various ideas expressed in the literature regarding the surface irregularities of the colloid there is little doubt that they are caused by shrinkage in fixation. In the majority of follicles the surface of the colloid was perfectly smooth, in some a little retracted from the epithelium, but in others completely filling the lumen. In some follicles the colloid showed surface indentations. These differences can scarcely be connected with the age of the organ, as they were observed in different stages. In all the young trout, however, the colloid filled the follicles completely. One possibility is that the content of the follicles does not always possess the same chemical composition, and is influenced by the same fixation fluid in different ways.

The view has been held that the true secretion of the cells is hyaline and that it appears in the form of small droplets which are set free on the surface of the cells. This process is thought by some to be responsible for the irregular surface of the colloid. Two kinds of surface irregularities must be distinguished, first, the large ones which do not correspond with depressions of the epithelial cells. These are without doubt due to the fixation. The connecting threads of colloid between the central portion and the epithelium seem to run between the cells and to take hold there. Tangential sections through the follicle wall, cutting the epithelium just under the free surface, show that the cells do not always lie closely placed in their upper portions and a 
network of colloidal threads is shown between them. In higher vertekrates these large surface irregularities in the colloid seem more common than in fish. The second, smaller irregularities might resemble secreted droplets. They give to the surface of the colloid, especially from a top view, the appearance of being beset with oil drops. In some places there are merely slight depressions in the free margin, some distance apart, while in other's the whole surface is corrugated, but these irregularities do not appear in all of the follicles. Whether they are really physiological products of the cells is not determined. The irregularities may be more easily explained on the theory that where the free ends of the cells do not come in close contact, the colloid which fills the follicles is pressed into the intercellular spaces and surrounds the top of the cells like a cap. In shrinkage from fixation the caps would be pulled from the cells, leaving on the surface of the colloid the impressions. Anderson regards these 'droplets' as well as the numerous vacuoles, which he finds within the colloid even of living glands, as "cavities lined with a hyaline membrane and containing the 'chromophobe' secretion, a part of the secretory activity of the gland." Langendorff and others more correctly regard them as artefacts, having no physiological significance. Vacuoles within the colloidal substance are seldom seen, (pl. V, fig. 13, V).

The colloidal material seems to become denser with age, as far as this can be determined by its staining capacity. In young trout it is rather pink so that it can scarcely be distinguished from the blood serum in the vessels. Both structures show the same microscopic appearance. In older trout, however, the colloid stains very deeply with acid dyes. These observationsagree with those of Schmid on dogs of different ages. Anderson, Boéchat, Peremeschko and others also state that the number of follicles containing a slightly staining finely granular colloid diminishes with age, being small in old individuals. I failed to find some follicles distinguished by a greater affinity for the stain than others, as was claimed by Hürthle, but did find that sometimes within the same follicle the colloid stained differently in different places. 
The structure of the colloid varies with the species and is the same through all the follicles. A perfectly homogeneous colloid exists in cases, in others it is granular, and finally in some fish it is of a lumpy consistency. The consistency of the colloid also varies with age, in old animals being rather cloudy in appearance and evidently very brittle after fixation. Occasionally the outer portion of the colloidal mass stains a trifle lighter which is the only indication of a concentric structure. This alone, however does not argue for the view that the colloid is a by-product of the active thyreoid, which collects and remains in the follicle. Langendorff first presented such an idea which of course called forth great opposition.

Blood corpuscles are occasionally found in the Teleost thyreoid and sometimes completely fill the lumen of the follicles or may be scattered or bunched together. Blood is also occasionally found in the human follicles. Baber was no doubt mistaken when he spoke of a real flow of blood into the follicles, as such does not occur. How the corpuscles enter the follicles is not known, though it is probable that somewhere, by pressure or tension, the delicate wall of a capillary lying next to the epithelium is ruptured and the corpuscles find their way into the follicular lumen through an injured wall. Hürthle believes the 'melting' of the epithelium responsible, when it occurs at a place where capillaries lie deeply imbedded. It is evident that whenever blood corpuscles do enter the lumen they are destroyed, and they may be seen in all stages of disintegration until finally pyknotic shadows of nuclei alone exist with no indications of their cell bodies. The scattered corpuscles lie within the colloid, which must therefore, be rather liquid. The content of the follicles has a haemolytic property without being itself of haematogenic (Baber) origin.

Cells from the follicular epithelium also form a part of the follicle content. These are pushed off either singly or several together into the lumen and there destroyed; they also lie within the colloid. Two kinds of cells are distinguished, those with a small body and dense cytoplasm, resembling somewhat epithelial cells of the ordinary type and those with a swollen body, and 
clear cytoplasm (pl. V, fig. 13, Coz), which may resemble Hürthle's colloid cells. The two types are probably different stages in the same process. At times the cell body is broken up into pieces before being transformed into colloid. The nucleus is always destroyed last.

A part of the colloid is therefore formed by degenerating epithelial cells which are either destroyed in their primary position or after being pushed into the lumen. Anderson believes that this is invariably the fate of the cells after several periods of secretion. Hürthle, also, noticed this 'melting' of the epithelium and was able to trace the complete disintegration of the cytoplasm, though the fate of the nuclei remained doubtful. They, too, are unquestionably destroyed within the colloid, and as a matter of fact I could observe cell nuclei, such as those of the red blood corpuscles, in all stages of disintegration, (pl. V, fig. 13, N). L. Müller regards the formation of colloid material from disintegrated cells as of slight importance. Hürthle remarks that in follicles of mammals with a flattened epithelium, which he considers the final secreting stage, cell remnants or defects in the wall can rarely be found. This is equally true in Teleosts.

I have never seen the signs of degeneration described by Maurer in old carp. He records a swelling of the epithelial cells which breaks down the follicles, permitting lymphatic elements to enter and form lymph nodules, similar to processes in Anura. Perhaps my specimens were not old enough to show these phenomena.

Pigment was not observed within the follicles, though outside of them brown pigment is often found in the supporting tissue. This is probably of haematogenie origin. Baber found brown pigment granules within the colloid in the thyreoid gland of the conger eel. I also fail to find crystals in the follicles or around them as has been reported by some investigators. They are undoubtedly postmortem products.

In the conger eel Baber observed a reticulum between the epithelial cells, in which they were partially imbedded. He states that this reticulum is formed by coagulated intercellular substance and has nodal thickenings. At the thickened places 
the 'club shaped' cells described above are located and may be clearly distinguished from the ordinary epithelial cells. I did not find such a reticulum, and it is possible that the filling of the intercellular spaces with colloid substance as before mentioned, may have been what Baber observed. He states that the reticulum (intercellular substance) stained with hematoxylin, which makes it very different from the highly eosinophile network observed by me. Baber's technique, however, seems to have failed to produce the proper differentiation, since he actually succeeds in staining parts of the colloid with nuclear dyes.

The disputed membrana propria was not observed. W. Müller, Kölliker and others claim to have seen it everywhere while Schmid and others definitely deny its existence. The connective tissue approaches the follicles and surrounds them but this loose connective tissue sheath, which is by no means always present, could scarcely be called a propria.

The blood supply of the thyreoid gland is abundant and varies somewhat with the species. Baber is the only observer who has studied the conditions in the Teleost thyreoid by aid of the injection method, and unfortunately he used only one specimen of the conger eel.

The capillaries often approach the follicles so closely as to seem imbedded between the epithelial cells. This is best shown when both follicles and vessels are cut in cross section, (pl. IV, fig. 6). Hürthle describes a similar condition in the thyreoid glands of young dogs and pictures them in plate II, fig. 6. The epithelial cells often partly surround the capillaries by means of processes, thus forming deep impressions. Baber speaks of small intercellular projections from the capillaries which seem to serve in retarding the circulation of the blood.

There is usually a network of capillaries around each follicle, four or five often being seen in cross section just outside the epithelium, (pl. IV, fig. 5, a). In longitudinal section, the capillaries at times surround almost the entire periphery of a follicle. Such specimens illustrate how closely epithelium and endothelium are neighbors without a separating basement membrane, (pl. IV, fig. 5, E, Ca). 
Where the follicles are densely packed, numerous spaces and channels run between them. The smallest of these seem to have no endothelial wall, so that the lymph flows directly against the epithelium of the follicles. In other cases the lymph vessel is indicated by two parallel endothelial lines running between the follicles. This does not agree with $L$. Müller's view that the blood capillaries are in close contact with the epithelium while the lymph vessels are separated from the follicles by blood vessels or connective tissue. The follicles are sometimes, as described in the anatomical part, situated directly on the big lymph spaces around the ventral aorta as the text figures 4 to 7 show. (See also pl. IV, figs. 2, 3.)

In the conger eel and skate Baber was unable to detect the lymph vessels. Since he injected the venous system which is connected with the lymph vessels he thus regarded the lymph capillaries as veins. Ferguson has been more successful in distinguishing between these two sets of vessels in the dogfish.

In some instances, less often, however, than it occurs in higher vertebrates, a substance was found in the lymph vessles, which had apparently the same structure as the contents of the follicles. The lymph spaces were filled with this substance in one instance and showed many smaller channels running together into the larger ones (pl. V, fig. 18, L). According to Anderson the colloid in the lymph vessels undergoes a change, becoming diluted and finely granular and is difficult to distinguish from blood serum.

The way in which the colloidal material leaves the follicle is not made clear by my study. Attention may be called to the varying views of different authors, especially those of Biondi and Anderson, given in their description of the follicular epithelium. It must be mentioned also that Hürthle believes in temporary intercellular channels which form between the cells for the passing of the colloid. I saw in a very few cases a colloidal pseudopodium, as it were, push through the epithelium.

I am also unable to state from the thyreoid gland in the Teleosts whether the veins contain colloidal substances and carry them into the circulation. 
The anatomy of the thyreoid gland of the Teleosts is decidedly different from that of most other vertebrates. It is not an anatomical unit. The term 'thyreoid gland,' therefore, is scarcely appropriate. Physiologically isopotent units are distributed over a wide area. Physical influences must be made responsible for this distribution, which is due to mechanical conditions of pressure and pull.

If the thyreoid gland of the Teleosts really have its prototype in the endostyle of the Tunicates, its phylogeny is somewhat as follows. We have at first a uniform organ with a given function, later a change of structure and function takes place, and the organ loses its unity (Myxinoids and Teleosts). In higher forms the new function is maintained but the organ retains its original uniformity and integrity.

The development of the organ from its anlage to the mature state seems to be simpler in Teleosts than in higher vertebrates.

The histology of the glandular elements of the thyreoid in the Teleosts is but little simpler than in higher vertebrates. It shows many parallels to the different features observed by numerous authors in other thyreoid glands.

The function of the thyreoid, concluding from its microscopical appearance, must be closely the same in Teleosts as it is in other vertebrates. 


\section{SPECIAL PART}

The species examined were:

\begin{tabular}{|c|c|c|}
\hline ORDER & FAMILY & SPECIES \\
\hline Apodes & Anguillidae & Anguilla chrysypa. \\
\hline \multirow[t]{8}{*}{ Isospondyli } & Clupeidae & Clupea harengus. \\
\hline & & Brevoortia tyrannus. \\
\hline & Salmonidae & Oncorhynchus kisutch. \\
\hline & & Salmo mykiss. \\
\hline & & Salmo irideus. \\
\hline & & Cristivomer namaycush. \\
\hline & & Salvelinus fontinalis. \\
\hline & Argentinidae & Osmerus mordax. \\
\hline Hemibranchii & Gasterosteidae & Apeltes quadracus. \\
\hline Lophobranchii & Syngnathidae & Siphostoma fuscum \\
\hline Haplomi & Poecilidae & Fundulus heteroclitus. \\
\hline & & Fundulus majalis. \\
\hline & & Fundulus diaphanus. \\
\hline \multirow[t]{15}{*}{ Acanthopteri } & Atherindae & Menidia notata. \\
\hline & Mugilidae & Mugil cephalus. \\
\hline & Scombridae & Sarda sarda. \\
\hline & Pomatomidae & Pomatomus saltatrix \\
\hline & Serranidae & Morone americana. \\
\hline & Sparidae & Stenotomus chrysops. \\
\hline & Sciaenidae & Cynoscion regalis. \\
\hline & & Micropogon undulatus. \\
\hline & Labridae & Tautogolabrus adspersus. \\
\hline & & Tautoga onitis. \\
\hline & Tetraodontidae & Spheroides maculatus. \\
\hline & Triglidae & Prionotus carolinus. \\
\hline & Batrachoididae & Opsanus tau. \\
\hline & Blenniidae & Muraenoides gunellus. \\
\hline & Pleuronectidae & $\begin{array}{l}\text { Pseudopleuronectes } \\
\text { americanus. }\end{array}$ \\
\hline
\end{tabular}

\section{ANGUILLA CHRYSYPA RAFIN}

The thyreoid gland in young eels, $30 \mathrm{~cm}$. long, has a transverse and not a dorso-ventral extension as one might expect in a species with a narrow floor of the pharynx. It begins far forward in the arterial bifurcation lying close under the basihyale and extends back to the second gill arteries (plate I, fig. 11.) Close behind the anterior end of the gland the transverse distribution of follicles becomes rather wide, (fig. 1, A), extending over the 

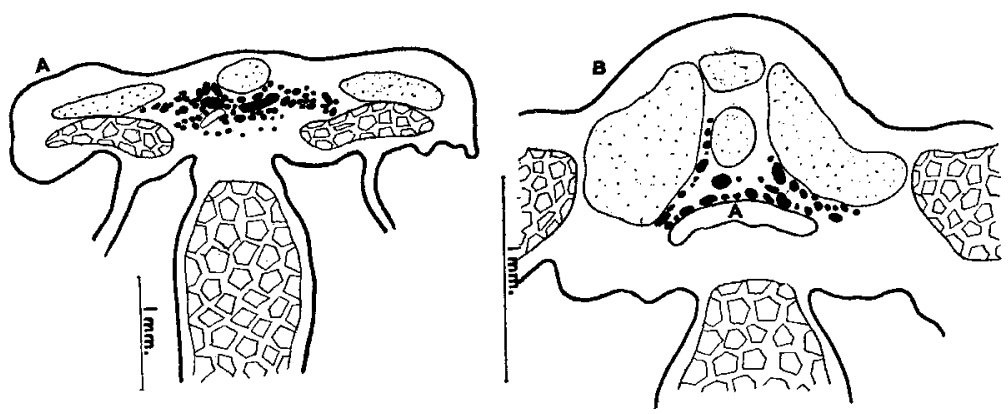

Fig. 1. Sections through the thyreoid gland of Anguilla. $A$, anterior to the aortic bifurcation; $B$, between the first and second branchial arteries. Thyreoid follicles in all figures shown in solid black. Transverse museles lined, Long-mascles in polygons. Skeletal parts stippled. Arteries heavy line. Veins light line. Lymph sinus broken line. $A$, ventral aorta. $A_{\mathrm{I}}, A_{\mathrm{II}}, A_{\mathrm{III}}$, branchial arteries.

entire space between the first gill arches, about $2.5 \mathrm{~mm}$. The layer of follicles is very thin so that the dorso-ventral extension is slight. Near the union of the two first gill arteries the follicles are somewhat more dispersed, and reach out dorsally along the sides of the basibranchiale. Some follicles actually lie dorsal to the skeletal parts. The thyreoid is in contact with the first gill arteries for a short distance, and here it reaches its maximal extension. Further back it is limited to the neighborhood of the ventral aorta.

Behind the aortic bifurcation the follicles lie closely above and to the sides of the aortic stem and extend along it to the second gill arteries. A string of follicles lies separated between the first and second arterial branches. Baber states that in the conger eel the gland is in the first bifurcation and forms a reddish flattened body. This would correspond to the region of maximal dispersion of thyreoid follicles in the species here mentioned.

The follicles exhibit a variety of shapes, elliptical ones being in the majority. They are rather small, $100 \mu$ representing the average diameter of the circular follicles. A few very large follicles are present; these 'giant' follicles as they might be called, are of elliptical shape measuring $600 \mu$ in the long and $200 \mu$ in the 
short axis. Baber observed in the conger eel follicles of very large size.

Some follicles send out branches which widen near their end to form secondary cavities, (pl. V, fig. 16). In the series from which one section is figured, (pl. V, fig. 15), may be found a large follicle sending out a branch, and further along two follicles $(F . f$.) connected by a tube $(D)$ of high cylindrical epithelium. The tube represents the branch of the former section and in another section both follicles are entirely separated. Going further in the series the small follicle increases in size while the large one sends out a second branch. Thus around a larger follicle as a center may be grouped several smaller ones connecting with the original follicle by 'ducts' as it were. These ducts might be compared with the intercalary portions of other glands. Baber likewise observed branching follicles in the conger eel. Baber claims that new follicles arise from groups of cells somewhat rounded in form and situated in the epithelial wall of the larger ones. I was unable to observe such processes. Lymphatics are present in the thyreoid gland of the eel, although Baber denies their existence.

Baber records the follicular epithelial cells as highly columnar in form. I find cuboidal epithelial cells measuring from 10 to $15 \mu$ high.
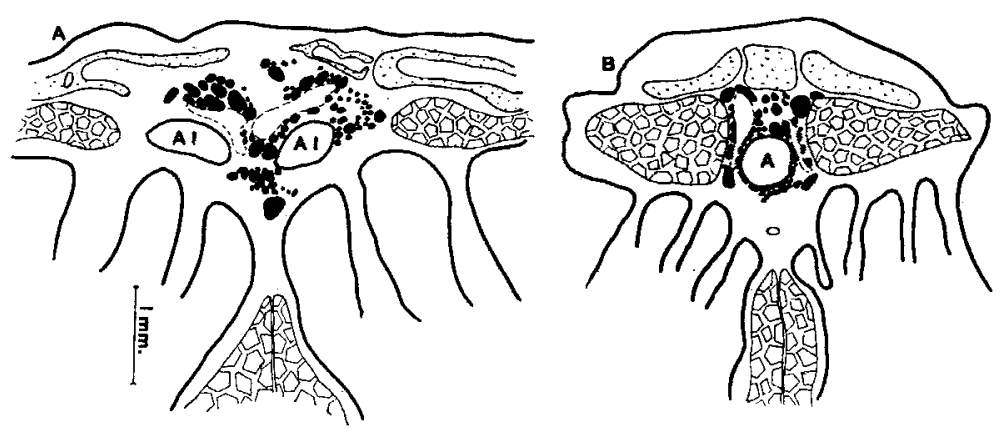

Fig. 2. Sections through the thyreoid gland of Clupea. $A$, in the aortic bifurcation; $B$, between the first and second branchial arteries. 
CLUPEA HARENGUS L.

In the herring (specimens $30 \mathrm{~cm}$. long) the thyreoid gland is well developed (pl. I, fig. 2). The triangular region formed between the floor of the pharynx, bases of the first gill arches and a ventrally lying cartilage is entirely filled with follicles. The distance between the floor of the pharynx and the ventral musculature is considerable, while the cartilages of the basibranchiale are only slightly developed; there is thus sufficient space for a dorso-ventral distribution of the thyreoid follicles (fig. $2, \mathrm{~A}, \mathrm{~B}$ ). In certain places the first gill arteries are completely surrounded by follicles; this is also true of the ventral aorta behind the anterior bifurcation (fig. 2, B). Back of the second branchial arteries the extension of the gland diminishes, and only small follicles make a complete ring around the aorta, from which rays of follicles go out towards the cartilages and muscles.

The average size of the follicles is about $200 \mu$ in diameter; very large ones are not seen. The follicular epithelium is in general rather high and varies between narrow cylindrical cells to broad cubical ones. The cells are not very densely arranged. In some regions are found a few neighboring follicles with high epithelial cells which almost obliterate the central follicular space (pl. V, fig. 20,Coz). Other follicles have lower cells and all stages exist between these and the normal ones. This suggests a zone of Hürthle's colloid-forming cells. The cytoplasm is highly eosinophile and the nuclei are located near the inner surface of the cells. In the intermediate stages, where there is a lumen in the center of the follicle we find in it colloidal material and red blood corpuscles.

\section{BREVOORTIA TYRANNUS LATROBE}

In this species (length $40 \mathrm{~cm}$.) there are very interesting conditions in the extension of the thyreoid gland, due to the enormous elongation of the gill region. The distance from the heart to the anterior aortic bifurcation measures about $5 \mathrm{~cm}$. and with this stretching of the ventral aorta the thyreoid becomes extended over a long region. The front end of the gland lies well beyond 

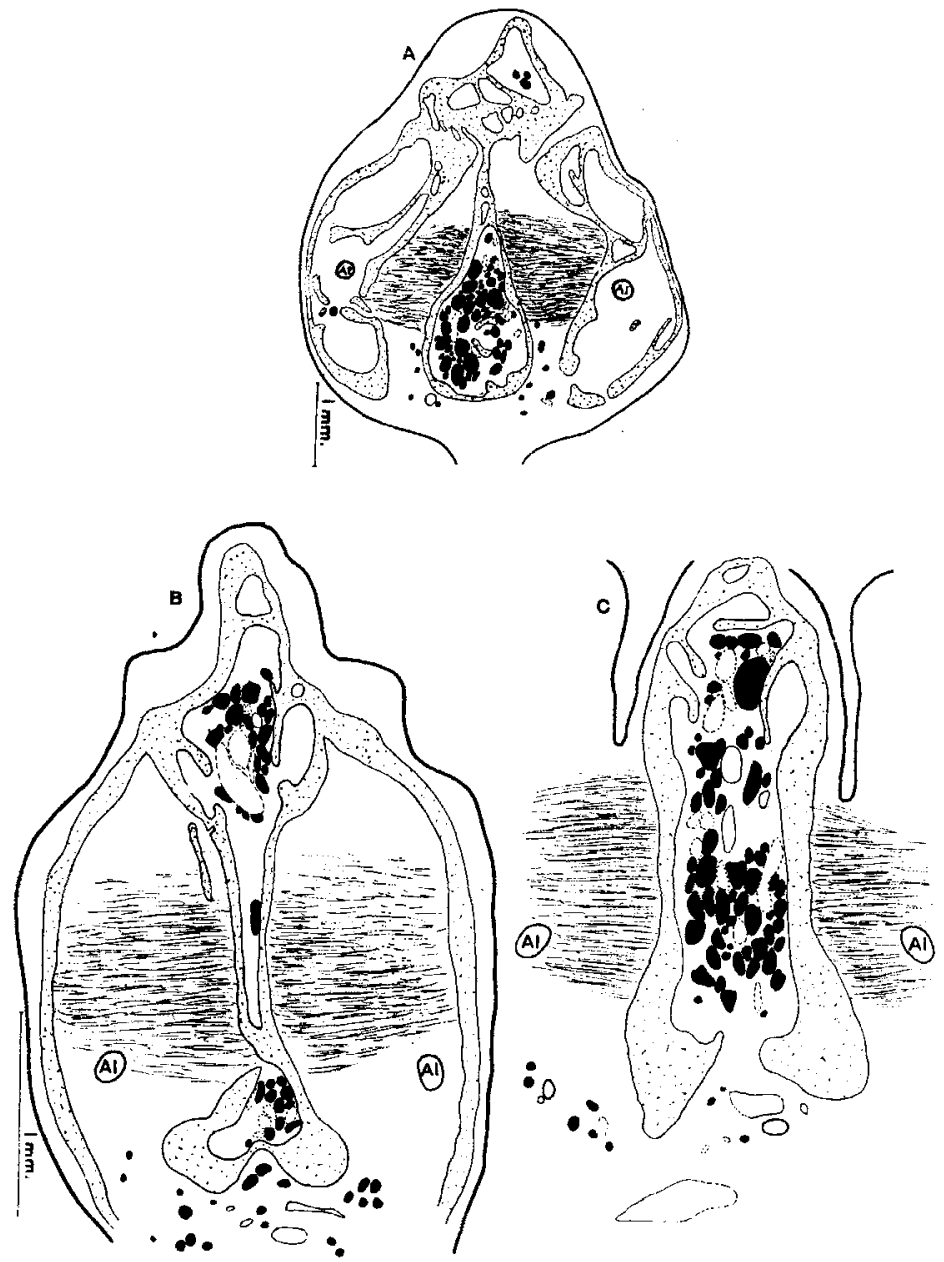

Fig. 3. Sections through the thyreoid gland of Brevoortia, all anterior to the aortic bifurcation.

the aortic bifurcation and the posterior end is at the second branchial arch, (pl. I, fig. 3).

The floor of the pharynx is very narrow, thus there is no chance for a lateral extension and the thyreoid follicles become dispersed only in a dorso-ventral direction. This extension is sometimes $4 \mathrm{~mm}$. high (fig. 3). 
The parts of the basibranchiale and hypobranchiale are not compactly developed, the floor of the pharynx being supported by a scaffold of osseous lamellae, between which a wide-meshed fatty tissue appears. There is also an osseous tube open at both ends (representing perhaps a sub-copula) and enclosing the most anterior portion of the ventral aorta (fig. $3, A$ ). In this tube the thyreoid gland extends from the branchial vessels towards the tip of the tongue. In transverse section the gland appears to be lying within a bony ring which completely separates it from the parts outside. At certain places, however, there are openings in this capsule through which the follicles escape into the outside tissue. Within the capsule are found osseous lamellae dividing it into several compartments, and thus three or more bunches of thyreoid tissue may be seen separated by bone.

At the anterior end the follicles lie outside the osseous capsule and are scattered far apart. They are always located in the neighborhood of either blood or lymph vessels and probably follow the vessels as paths of dispersion. The follicles are not always, however, in direct contact with blood vessels.

The osseous capsule lies above the ventral aorta, and we find thyreoid tissue only above the vessel. The first gill arteries for a short distance are completely surrounded by very small follicles. From the aortic bifurcation the follicles extend far forward into the capsule although there are no large vessels, thus there seems to be a tendency towards a forward migration. This is really the only available space into which the thyreoid can expand, unless it enter the ventral musculature.

The histology of the gland is somewhat different from that in other fish. The follicular epithelial cells are drawn out into long processes which come into contact with those arising from the cells of near-by follicles (pl. IV, fig. 1). This suggests that the cells of one follicle might communicate through these processes with those of the adjacent follicles. The only explanation for this phenomenon is as follows: originally the follicles lie close together, with their epithelial cells touching, and when the space between the skeletal parts becomes wider the meshes of the fatty tissue, in which the follicles are suspended, are pulled somewhat 
apart, carrying the follicles with them. The cells, which were in contact with others or with blood and lymph vessels may have held fast to them, becoming drawn out into long processes. They thus form a network between the follicles. These bridges of ten surround the capillaries.

There are only a few follicles which have a regular epithelium with a smooth outline. Outside the bony ring, described above, the follicles have the usual epithelium with a smooth surface.

In places the epithelium was found to be disintegrating. The association of the cells seemed rather loose, their surfaces were also drawn out into long processes like pseudopodia which sometimes divided into two and disappeared in the interfollicular tissue (pl. IV, fig. 5, E). These cells did not show any distinction between nucleus and cytoplasm, and their contents was of a foamy nature and showed two or three compact deeply staining granules. They were probably cells which having completed their secretion period were disintegrating.

\section{SALMO IRIDEUS GIBBONS}

Specimens $4 \mathrm{~cm}$. long, one month old. In the young rainbowtrout the thyreoid gland begins in the aortic bifurcation and extends almost to the third gill arteries, (pl. II, fig. 22). There is little space for a lateral extension, as the cartilages of the basiand hypohyalia form a rather narrow arch, and limit the gland to the space immediately above and below the aorta. At the aortic bifurcation the copula comes close to the vessel, so that the follicles are pressed away from the median line, and lie close to the sides of the cartilage. Later the skeletal parts move back, the space between them becoming somewhat clearer. Half-way between the first and second gill branches the thyreoid gland also extends below the aorta, and a large number of the follicles lie near the second arterial branches. These ventral follicles are smaller than the dorsal ones (fig. $4, B$ ). Towards the posterior limit the follicles become smaller and fewer and are again limited to the region above the aorta. Only two or thrce follicles are seen in a cross section and at the third gill arteries they have entirely disappeared. 

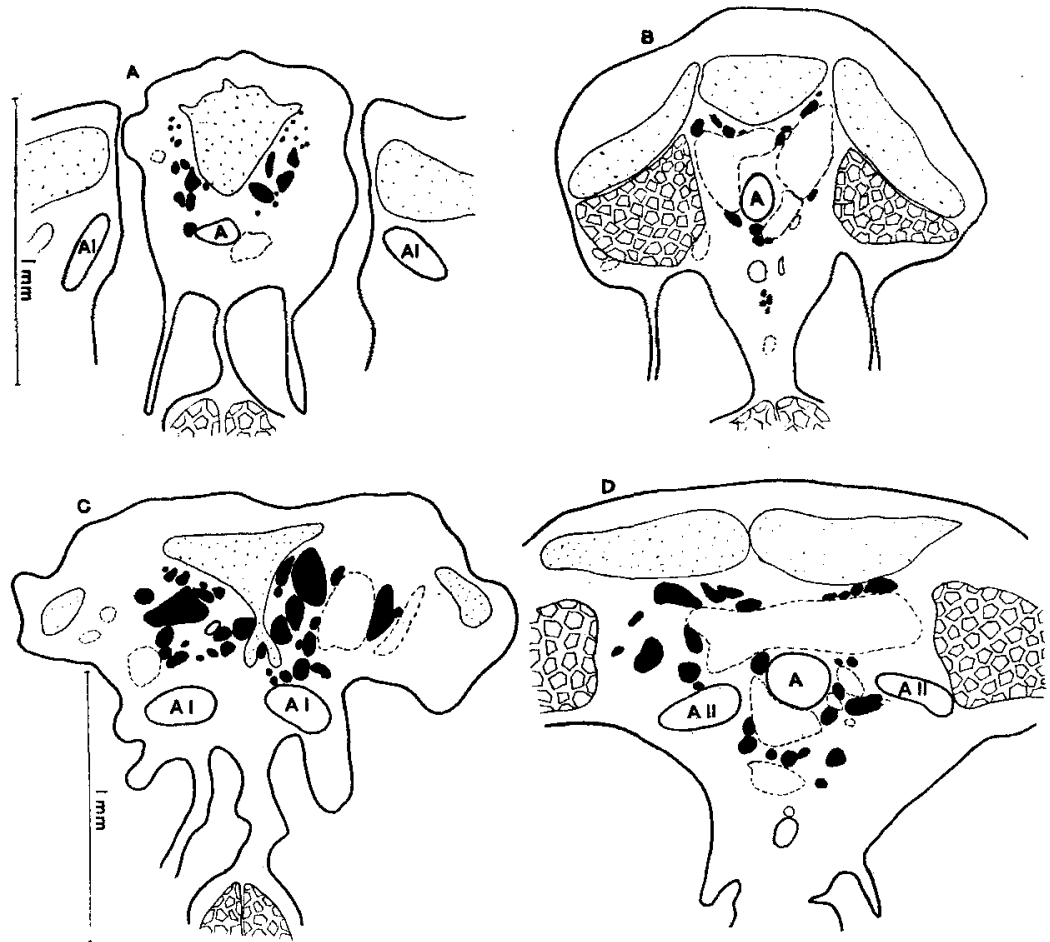

Fig. 4. Sections through the thyroid gland of Salmo irideus. $A$ and $B$, from a specimen one month old. $A$, just posterior to the aortic bifurcation; $B$, near the second branchial arteries. $C$ and $D$, from a specimen one year old; $C$, in the aortic bifurcation; $D$, at the second branchial arteries.

The follicles are usually circular but there are also irregular forms, due to pressure from the surrounding tissues. The diameters of the circular follicles vary between 10 and $80 \mu$, the larger ones being rare. The follicular epithelium is everywhere low, the cells measuring about $3 \mu$. The nuclei are all placed with their broad side towards the lumen, which might be called the flat cell position to distinguish it from the cylinder cell position in which the nuclei point towards the lumen.

Almost all the follicles are filled with clear homogeneus colloid, which has only here and there retracted a little from the wall. Blood capillaries belonging to the follicles, as observed in other species, 
are not visible. Around the aorta there are rather large veins or lymph vessels with extremely thin walls, close to which the follicles lie (fig. $4, B$ ). There is no tissue (basement membrane) between the epi- and endothelium, the first being almost as thin as the latter. The nuclei of these epithelial cells are spindleshaped and lie far apart.

Specimen one year old. In this fish the distribution of the thyreoid is about the same as in the younger one, (pl. II, fig. 23). The anterior end is pushed further forward in the aortic bifurcation, and the posterior end still lies close to the third gill branches. The mass of thyreoid tissue is much enlarged. The follicles are much larger in the bifurcation, and in a section there are more than three times as many as in a one month old individual. They are packed more densely and completely fill the space between the cartilages and arteries. The process of the copula mentioned above, which comes down to the level of the aorta, here divides the thyreoid into a right and left half. While in the younger trout the lateral extension of the follicles was less than the dorsoventral, at this age the floor of the pharynx has become broader through a widening out of the gill arches, and the lateral distribution is more than twice as extensive as the dorso-ventral, although the follicles still go high up along the cartilages (fig. 4, $C)$. The follicles also extend some distance along the first branchial arteries. Here the entire thyreoid lies dorsal to the blood vessel and is grouped around two or more large lymph spaces (fig. 4, C). Immediately behind the aortic bifurcation the lateral and then the dorso-ventral dispersion of the follicles decrease, so that they lie more densely packed and are fewer in number.

The hypobranchialia approach closer and closer to the copula as we pass backward and force the thyreoid to a more ventral position. Finally the aorta lies almost on the cartilages and the thyreoid shows only one or two follicles in the section. This restriction of the thyreoid zone (pl. II, fig. 23) between the first and second branchial arteries is typical for all salmonids. It may also occur in some other species but is never so pronounced as in the trout. 
Near the second branchial arteries the skeletal arch becomes flattened again, the copula does not reach so far down, and first the dorso-ventral and later the lateral distribution of the follicles again increases. Comparatively few follicles now appear below the aorta (fig. 4, D). Behind the second branchial arteries the follicles decrease in number and size, and completely disappear before the third branchial arteries are reached.

The follicles are circular, oval or irregular in cross section. The diameters of the circular ones vary between 40 and $200 \mu$, the larger ones are more numerous, especially in the anterior region. Branched follicles occur, sometimes as many as five follicles leading into a larger one.

Here also the follicular epithelium is low, almost flat, and the follicles are completely filled with homogeneous colloidal substance. Sometimes, however, the colloid contains particles, probably destroyed blood corpuscles or epithelial cells. The blood supply is rich, many capillaries lying close to the follicles. There seems to be a comparatively better circulation here than in the younger stages.

\section{SALMO MYKISS WALBAUM}

Specimen $11 \mathrm{~cm}$. In the black spotted trout the thyreoid gland shows a great antero-posterior extension. The posterior limit is about that shown by Maurer in a $20 \mathrm{~cm}$. trout, species not named, apparently a brook trout. However, the main part of the gland is situated above the aorta, not below it as Maurer claimed. The anterior limit of the gland lies well in front of the aortic bifurcation and the posterior end behind the third branchial arteries (pl. II, fig. 21). The dorso-ventral distribution is also more pronounced than in most of the other species, especially as to the number of follicles below the aorta. The main mass of the organ lies in the aortic bifurcation (fig. 5, A). The copula reaches far down and divides it into two halves. Along this cartilage the follicles extend dorsally close up to the floor of the pharynx. Laterally also the extension of the follicles goes as far as possible. 

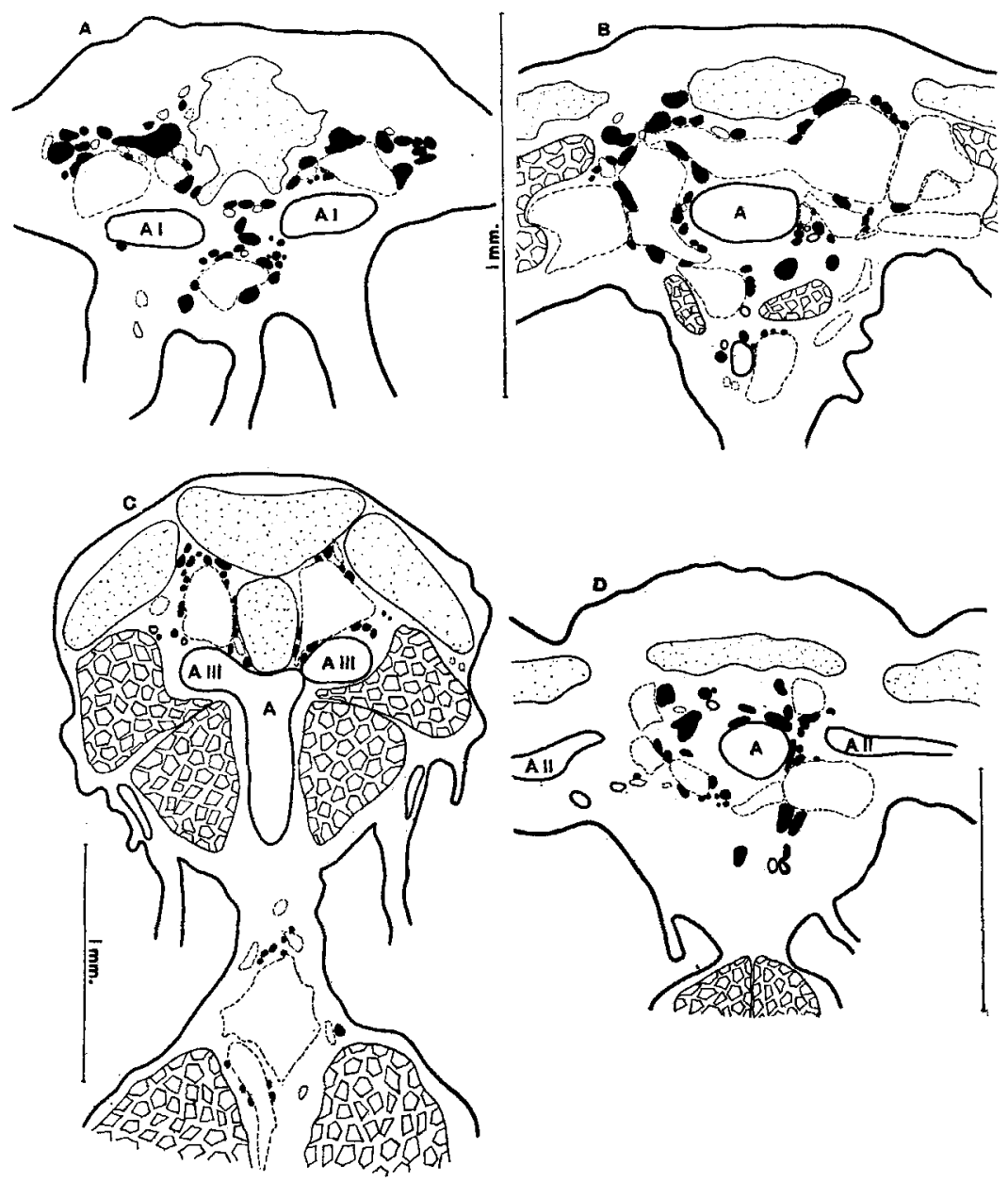

Fig. 5. $A$ to $C$. Sections through the thyreoid gland of Salmo mykiss. $A$, in the aortic bifureation; $B$, closely anterior to the second; $C$, at the third branchial arteries. $D$. Section through the thyreoid gland of Cristivomer at the second branchial arteries.

The follicles do not lie directly on the first branchial arteries, but are grouped around large veins or lymph sinuses, the dorsal follicles being much larger than the ventral ones. Behind the first arterial branches the dispersion of follicles is very much reduced. They are forced away from the dorsal region by the 
development of the basi- and hypobranchialia and occur only laterally and ventrally of the aorta. Further back even the lateral follicles disappear and only a few small ventral ones are grouped around a small vessel. Space again becomes available towards the second branchial arteries, since the skeletal parts retract more and more, and the follicles reappear in their former locations. The lateral extension however is not as great as in the region of the first arteries, since longitudinal muscle bundles prevent it (fig. 5, B). Dorsally the follicles again reach up to the pharyngeal floor. Close to the second branchial arteries the dorsal extension again diminishes and almost disappears when the second gill arteries are reached. Here the follicles lie far below the aorta, as they are forced away from the vessel by a longitudinal muscle. From this place backward a few follicles again appear above the aorta; they are small and scarce, five or six in a section, and widely scattered. Behind the third arteries the ventral aorta lies buried far beneath a muscle, between which and the skeletal parts a portion of the thyreoid lies. Another portion lies below the aorta between the third and fourth aortic branches, and here once more the amount of thyreoid tissue is slightly increased. A small mass of follicles disconnected from the main mass appears behind this place, lying below the aorta.

Cross sections through the follicles are usually circular, some are irregular. Their size decreases from the anterior towards the posterior end of the thyreoid region. The diameters vary between 10 and $60 \mu$ in a single section. The epithelium is rather flat, though some follicles have a cubical epithelium 3 to $5 \mu$ high. The nuclei of the flat cells show a peculiar feature; in all other cases they are either round or oval, but here with a few exceptions they are bent, taking forms ranging from wide arches to perfect horse-shoe shapes and are from 8 to $10 \mu$ long. In all probability they are degenerating, since they do not stain as deeply with nuclear dyes as do the round nuclei. Many of the follicles do not contain colloid.

The blood supply of the thyreoid zone is rich but there are no capillaries to the follicles proper, although there are smaller blood vessels in the region. Large veins and lymph vessels lie around the aorta and the follicles lie close to their walls (fig. 5, $B$ ). 


\section{CRISTIVOMER NAMAYCUSH WALBAUM}

Length of specimen, $12 \mathrm{~cm}$. The outlines of the thyreoid region in the great-lake trout are about the same as in the former species, but the ventral and posterior extensions are more limited. The anterior end lies in front of the aortic bifurcation, the posterior end at the third branchial arteries, (pl. II, fig. 24). The conditions from the aortic bifurcation to the second branches are the same as described in the species above but at the second arteries the accumulation of thyreoid material is rather large. Here also are found the largest follicles. The lateral extension is wider than at the first branches. The aorta is surrounded by follicles (fig. 5, D) but they do not lie very close to its wall. Posteriorly the extension decreases, three to four follicles being seen in a section above and below the aorta. The ventral follicles soon disappear and at the third aortic branches the dorsal ones also run out.

The follicles are a little larger than those of the black trout. Irregular and circular cross sections of the follicles are seen, the latter 20 to $100 \mu$ in diameter. The epithelial cells are generally cubical, about $6 \mu$ high. The nuclei are circular, $3 \mu$ in diameter, oval or somewhat irregular. The bent nuclei described in the black trout are present, but not so numerous. Some follicles show only regular nuclei, others only irregular, so that one might imagine these forms associated with different physiological stages. Almost all the follicles contain colloid.

There are many capillaries in the fatty tissue in close contact with the follicles. The follicles are not located on large veins and only a few lie close to the lymph sinuses.

\section{SALVELINUS FONTINALIS L.}

Length $4 \mathrm{~cm}$., age 1 month. In this young brook trout the thyreoid gland has not developed very far, certainly not so far as Maurer describes for this stage. The follicles are scarce, the most anterior lying in the aortic bifurcation. Between the first and second branchial arteries there are a few follicles in each section, 
situated above the aorta; near the second a few appear below the aorta (fig. $6, A$ ).

Length 25 to $30 \mathrm{~cm}$. In the brook trout a condition of remarkably wide distribution of thyreoid material is seen. The region of the thyreoid in this species is comparatively larger than in any other fish. The anterior end of the gland is far in front of the aortic bifurcation and small follicles extend to the floor of the pharynx (fig. $6, B$ ).

The first branchial arches are completely surrounded by thyreoid follicles. In the aortic bifurcation the follicles are very numerous, densely packed and occupy a rather large field. They reach up to the dorsal edge of the copula and laterally to the gill bases. On both sides of the aorta they are scattered between the fibres of longitudinal muscles (fig. 6, $C$ ). The follieles force their way through"the muscle tissue along blood vessels and connective tissue fibres. Below the aorta their arrangement is less dense. Close behind the aortic bifurcation the amount of thyreoid tissue is reduced in the typical way, the copula extending down to the aorta. By this arrangement three, more or less separated, thyreoid masses are formed, two dorsally to the right and left of the copula and one below the aorta. The ventral part decreases, then the dorsal masses, the arrangement of the follicles becoming looser. Although the dorsal space becomes more open the follicles still decrease in size and are scattered far apart, indicating that this is a zone between two accumulations of thyreoid tissue, those around the first and second aortic branches. Two centers of growth may easily be determined.

Just before reaching the second branchial arteries the lateral extension becomes very great (fig. $6, D$ ). The follicles migrate into the first gill arches along the branchial arteries and occur at the base of and extend into the second gill arches. This wide distribution of thyreoid elements is certainly the most remarkable feature of the organ in the Teleosts. Follicles not only lie at the base of the gills, but are distributed along the laminae at the base of the villi.

At the second branchial arteries the thyreoid gland, as mentioned above, once more shows an extensive development. Above 

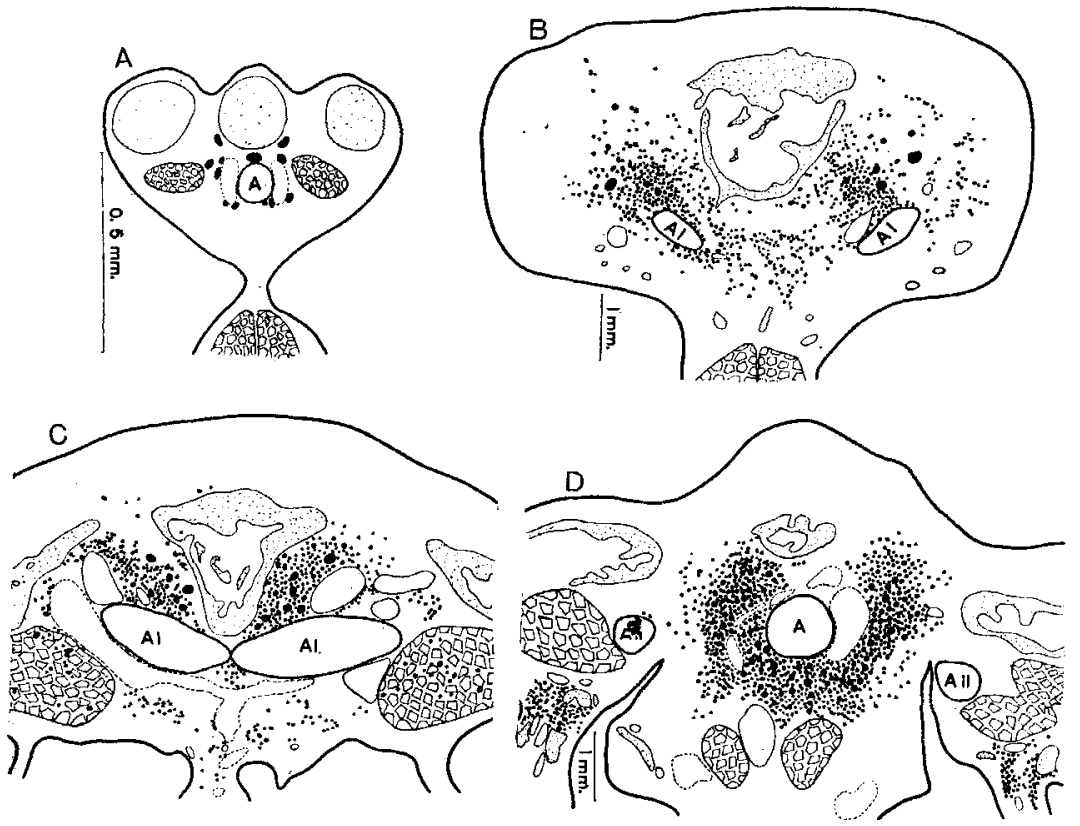

Fig. 6. A. Section through the thyreoid gland of a one month old specimen of Salvelinus fontinalis, between the first and second branchial arteries.

$B$ to $D$. Sections through the thyreoid gland of an adult specimen. $B$ and $C$, in the aortic bifurcation; $D$, near the second branchial arteries.

the aorta a dense arrangement of follicles is seen and below the number increases. Laterally the follicles extend along the arteries. Behind this place the aortic stem is entirely surrounded by thyreoid tissue which completely fills the space between bones and muscles. Small follicles are imbedded in the adventitia of the aorta. There is a dissolution of the dense arrangement in the peripheral zones, especially ventrally. Close behind the second branchial arteries the mass of thyreoid tissue decreases very suddenly and only a thin ring of follicles surrounds the aorta. Towards the third branchial arteries the aorta becomes buried between the ventral muscles, and the ventral follicles disappear sooner than the dorsal ones which continue and surround the third branchial arches for a short distance. Behind the third 
branchial arteries a small accumulation of thyreoid tissue once more appears.

A second series shows conditions similar to those above described. The follicles in the anterior region are less densely arranged. The basibranchiale comes very close to the aorta and separates to some extent two portions of thyreoid tissue along the aortic stem. The follicular mass is little reduced behind the aortic bifurcation but a little in front of the second branchial arteries the typical restriction is found. At this place the first ventral follicles appear. When the second aortic branches are reached the lateral extension of follicles becomes very wide. The mass of thyreoid tissue is here much increased, and the ventral portion is well developed but not so far as in the trout described above. The thyreoid stops close behind the second branchial arteries.

In a third series the separation of follicles in the anterior portions is still greater than described in either the first or second. The dorsal limit reaches to the upper edge of the basihyale, where there is an accumulation of follicles on both sides. The first branchial arteries are for a long distance completely surrounded by follicles, but the number of follicles decreases visibly towards their union; thus in this case there is an accumulation of follicles in front of the first aortic bifurcation. The ventral follicles appear at the first branchial arteries and disappear before reaching the second. It seems that here the entire thyreoid mass is pushed much farther towards the head than in the other trout deseribed. Between the first and second branchial arteries the conditions are similar to those in the other specimens, the distribution of the follicles being restricted. There is no pronounced increase of thyreoid tissue or lateral distribution at the second branchial arteries and the posterior limit of thyreoid follicles is in front of the third branchial arteries.

High epithelial cells were predominant in the follicles of all the thyreoids. The cubical cells measure 9 to $10 \mu$ broad and $12 \mu$ high, and the narrow cylindrical cells are 2 to $3 \mu$ broad and $20 \mu$ high. The nuclei are usually large and round, except in the very high cells where they are compressed. In a few places 
not all the nuclei of a follicle show the same structure or the same reaction towards the stain and thus may be in different physiological stages. In addition to normal, large nuclei with distinct nucleoli and granular structure we find compact deeply staining nuclei which sometimes contain a vesicle. There are also small pyknotic nuclei in small (degenerating) cells. Often such compact nuclei with a halo of colloid are found within the lumen and it seems then that the epithelial cells have emptied their entire content. These masses can be easily distinguished in the colloid even after their outlines become indistinct as they have a different refractive index. Maurer describes somewhat similar structures in trout and carp. In other cases several neighboring cells with much swollen bodies have been pushed off from the epithelium and may be seen in the colloidal substance (pl. V, fig. 13).

The general form of the follicles is globular, though the surrounding fat and muscle tissue influences the outlines to some degree (pl. V, figs. 10-12).

Smooth muscle fibres are found in the entire thyreoid region; in one case (the first specimen) only ventral to the aorta. They run in all directions in the interfollicular tissue. The follicles are often arranged along them or are surrounded by them. Where the follicles lie in clusters of five or ten or more, smooth muscle fibres are found running between them. The muscle fibres with the follicles, their capillaries and the connective tissue fibres form a somewhat compact structure.

The blood supply to the secreting epithelium is extremely rich, several capillaries going to each follicle (pl. V, figs. 10, 12 $\mathrm{Ca}$.

The thyreoid gland in two other species was dissected out as far as it was visible macroscopically. In this way of course one does not get the scattered follicles but only the main masses. Figs. 28 and 29 of plate III from these two dissections as well as figs. 25 to 27 of plate II, which are from specimens cut in serial sections, show that the distribution of the thyreoid in the trout is very variable. 


\section{ONCORHYNCHUS KISUTCH WALBAUM}

Specimen 6 months old, $7 \mathrm{~cm}$. long. The thyreoid gland in the silver salmon extends further back than in most of the trouts, reaching beyond the fourth branchial arteries (pl. V, fig. 20). Another feature in the arrangement is that the follicles lie rather close together, surrounding the stem of the ventral aorta through-
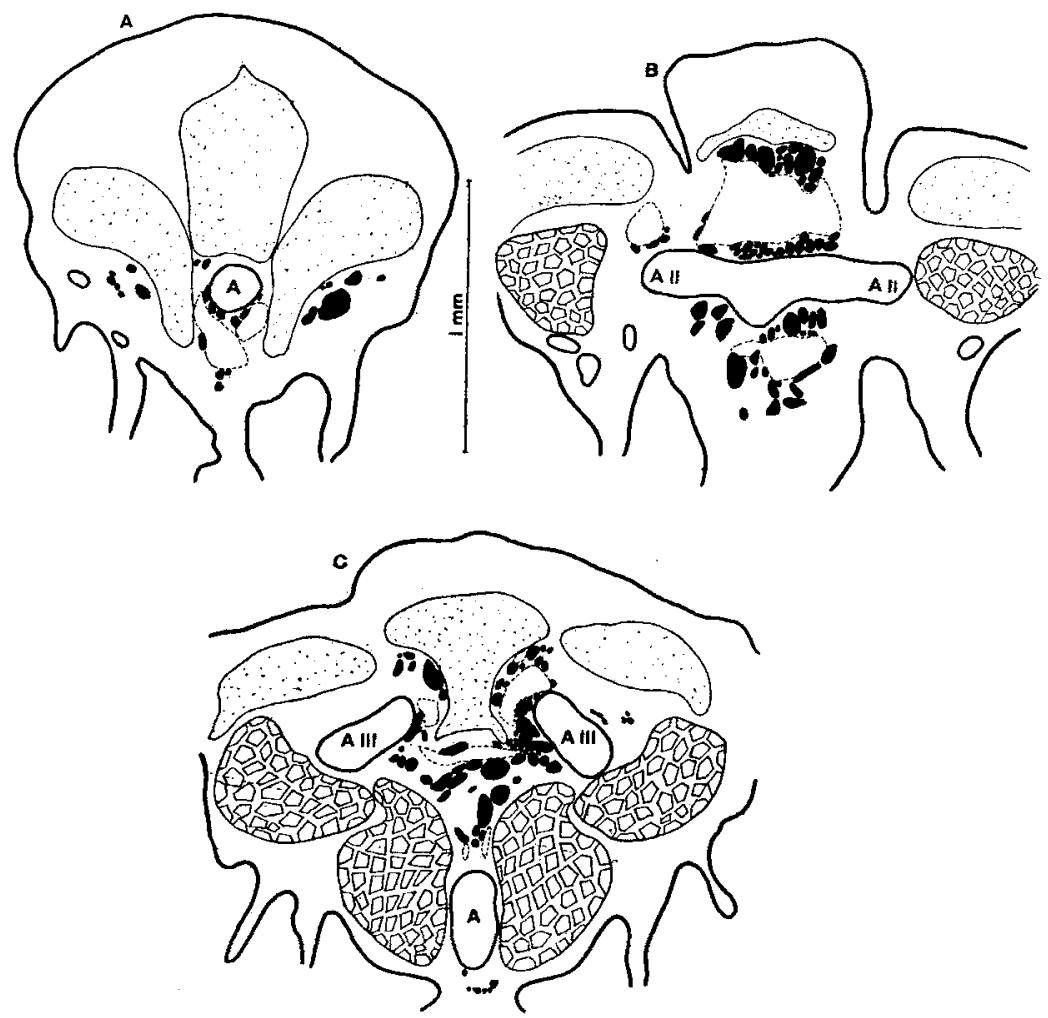

Fig. 7. Sections through the thyreoid gland of Oncorhynchus. $A$, just posterior to the aortic bifurcation; $B$, at the second branchial arteries; $C$, posterior to the third branchial arteries.

out almost its entire length. The amount of thyreoid tissue is small at the aortic bifurcation and between the first and second branchial branches (fig. 7, $A$ ). At the second gill artery the thyreoid tissue is most abundant. 
In front of the aortic bifurcation the basi- and hypobranchialia reach down and here only a few follicles are found on both sides of the hypohyalia. Back of the place where the cartilages have retracted the longitudinal muscle bundles prevent the lateral expansion of the thyreoid (pl. V, fig. 14). At the second branchial arteries however, the mass of thyreoid tissue is very much increased, again surrounding the aorta (fig. $7, B$ ). The ventral extension is pronounced. As a rule in the trouts no follicles lie directly against the aortic wall but here there is a complete ring of them around it. Above this ring lies a large lymph sinus and between it and the skeletal parts thyreoid tissue is again found. Towards the third aortic branches the cartilages again compress the aorta, and here the follicles lie around the aorta and along the outlines of the cartilages. Further back the aorta sinks down between the muscles, the ventral follicles disappear and the dorsal ones do not follow the vessel, but increase in number and group themselves around a subcopula between the third branchial branches. This dorsal rather compact group of follicles extends back behind the fourth branchial arteries. Below the aorta a small cluster of four or five follicles appears as is seen in other species of trout (fig. 7,C). At the level of the fourth aortic branches the copula extends so far ventrally that the dorsal follicles are pressed between the muscles and again come down into contact with the aorta. The posterior end of the thyreoid is in this region of the fourth arch.

The form of the follicles is usually elliptical, though circular cross sections are also found, ranging from 15 to $100 \mu$ in diameter. The larger ones are more abundant.

The follicular epithelium is very flat (pl. V, fig. 14), and in most of the cells are again seen the irregular nuclei described in some of the above species of trout (pl. IV, fig. $9, N)$. The majority of follicles are in close relation with large lymph sinuses, epiand endothelium being in contact (fig. $7, B, C$ ). There are no capillaries to the follicles proper. 
A smelt $20 \mathrm{~cm}$. long. This smelt presents the thyreoid conditions described below. A few follicles appear far in front of the aortic bifurcation (fig. $8, A$ ), and further back more are arranged around the copula. At the bifurcation every section shows twelve to fifteen follicles between the stem of the aorta and the
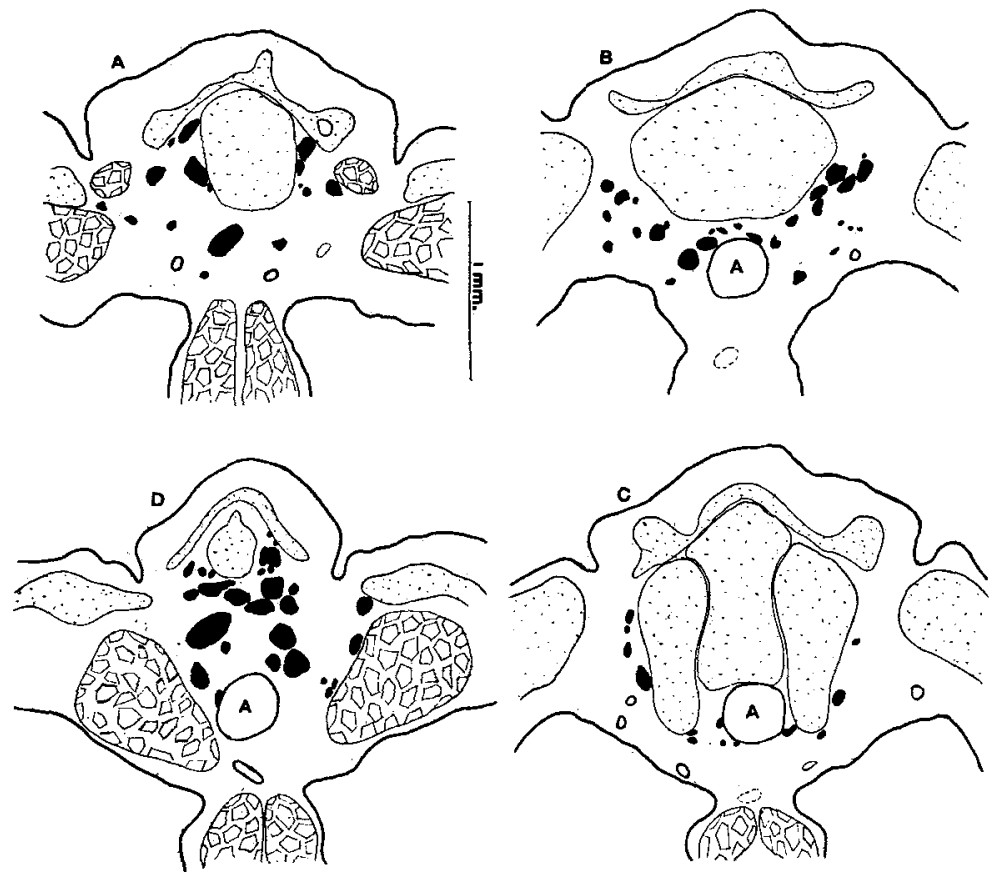

Fig. 8. Sections through the thyreoid gland of Osmerus. $A$, anterior to the aortic bifurcation; $B$, just posterior to it; $C$, between the first and second; and $D$, close to the second branchial arteries.

copula. The follicles vary in size from 40 to $200 \mu$. Behind this the main mass of thyreoid tissue lies above the aorta, a few follicles lie to either side, and ventral to the aorta they are very scarce. Further back the basibranchiale comes nearer and nearer the aorta, finally reaching it, so that the follicles are forced out laterally (fig. $8, C$ ). In the region of the hypobranchialia are 
seen only a few follicles far to the sides of the aorta and skeletal parts. Behind this the two hypobranchialia have retracted a little from the copula and very small follicles appear in the crevices between them. As the copula retracts from the aortic stem, more follicles appear on the dorsal side of the aorta. At the second branchial arteries the follicles cease (pl. I, fig. 4). The follicular epithelial cells are low cuboidal with the longer axis parallel to the base. The colloid appears homogeneous.

\section{SIPHOSTOMA FUSCUM STORER}

Specimen $30 \mathrm{~cm}$. long. In the pipe-fish the thyreoid gland consists of entirely isolated follicles, lying above and to the sides of the aorta (fig. 9). The external form of the fish influences, of course, the form of its inner organs. The thyreoid gland has not found room for dorsal, ventral or lateral expansion and therefore extends far backwards as a rather narrow streak. The anterior end lies at the aortic bifurcation and the posterior end close to the bulbus arteriosus (pl. I, fig. 5). Thus we have a condition in which the organ reaches further towards the tail than usual and where the thyreoid region tapers towards the head end, while as a rule the reverse is true. The number of follicles is not very large, five or six to the section behind the aortic bifurcation. The number decreases towards the second branchial arteries and still more so towards the third, where a transverse muscle occupies the space between the bones and the aorta. At this place there are only one or two follicles in a section, yet there is a continuous chain of them. Near the third branchial arteries the aorta goes down ventrally, the transverse muscle has decreased, and thus the thyreoid finds more space for development. There are six or eight follicles in a section and they lie between the third gill branches which run dorso-laterally. Behind this place the dispersion of follicles increases (pl. IV, fig. 7), although the aorta lies far ventrally, a fact showing that the thyreoid follicles do not necessarily use the aortic stem as a migration path. On each side of the median line a muscle runs in an antero-posterior direction upon and under which the thyreoid follicles lie. The ventral 
group consists only of small follicles which have traveled downwards along a vein running between the two halves of the muscle. Further back the muscle bundles separate and here the greatest mass of thyreoid tissue is found. The space between the pharynx and bulbus is well filled by follicles which lie in a chaos of capillaries (pl. IV, fig. 7, $\mathrm{Ca}, \mathrm{F}$ ).

Histologically this gland is as different from that in other species as it is anatomically. The gland, when fixed, may have been

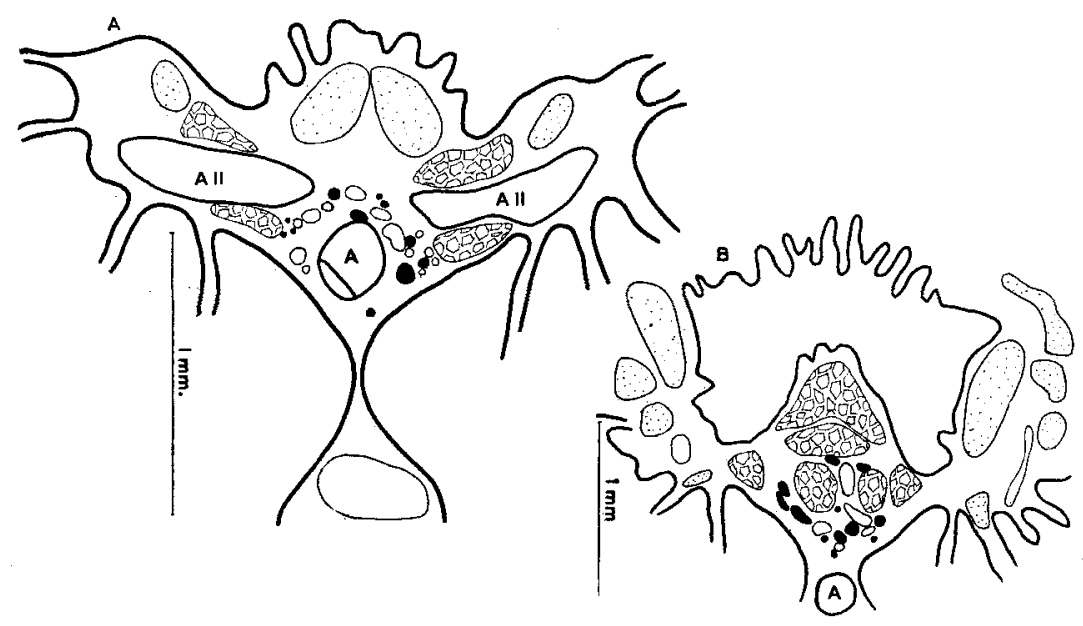

Fig. 9. Sections through the thyreoid gland of Siphostoma. $A$, at the second; and $B$, posterior to the branchial arteries.

in a peculiar state of function since there are no reasons to assume that the histological structures observed are permanent. Colloid was not found in any of the follicles, at least not as a uniformly compact mass. Certain follicles contained highly acidophile lumps about the size of epithelial cells. The epithelium, however, seemed in a state of colloidalization. The cells were high, cuboidal and swollen, with bulged out bases and surfaces (pl. IV, fig. 8). The nuclei were centrally located or towards the lumen. Thus they seemed to be typical colloid forming cells. The nuclei are in some cases round and massive, usually however they are very irregular. In some it seemed as though amitosis was taking place. 
The formation of colloid ordinarily occurs in only a part of the thyreoid at a time. Here, however, the entire gland seemed to be in a similar physiological state.

\section{FUNDULUS HETEROCLITUS L.}

Specimens $10 \mathrm{~cm}$. in length. The follicles in the region of the aortic bifurcation are grouped around a vein, most of them lying to the sides of it and under a transverse muscle. The elliptical shape of the vein in sections indicates the pressure between this muscle and the $\mathrm{m}$. sternohyoideus which forces the follicles out from the median line. The follicles become more numerous towards the aortic bifureation and they extend part way out along the first branchial arteries, and more on their ventral than dorsal side. Between the first and second gill branches follicles are found under and above the transverse muscles around which they have traveled. The ventral aorta in this region is completely surrounded by thyreoid tissue, more being found on the sides than either dorsally or ventrally (fig. 10, $B$ ). At the second gill branches the follicles again spread out laterally. Behind this place only a few scattered follicles are found (pl. I, fig. 6).

The size of the folliclesvaries extremely. The smallest are found at the anterior end and the largest in the middle of the thyreoid region. They are either circular in cross section, oval or with irregular evaginations.

The epithelial cells are usually cubical, but in very small follicles sometimes columnar, while in large empty follicles the cells are flat. Narrower cells with spindle shaped nuclei are seen in places.

The colloid is granular, and in some regions is seen to leave the follicle. Whether this is due to artificial pressure cannot be stated. Occasionally two neighboring epithelial cells will flatten out somewhat as if they were about to form a passage between them.

The blood supply to the thyreoid region is rich. The follicles are almost completely surrounded by a net of capillaries. These vessels are so pressed against the follicle that they form grooves in it (pl. IV, fig. 6). The projections of the epithelium between 

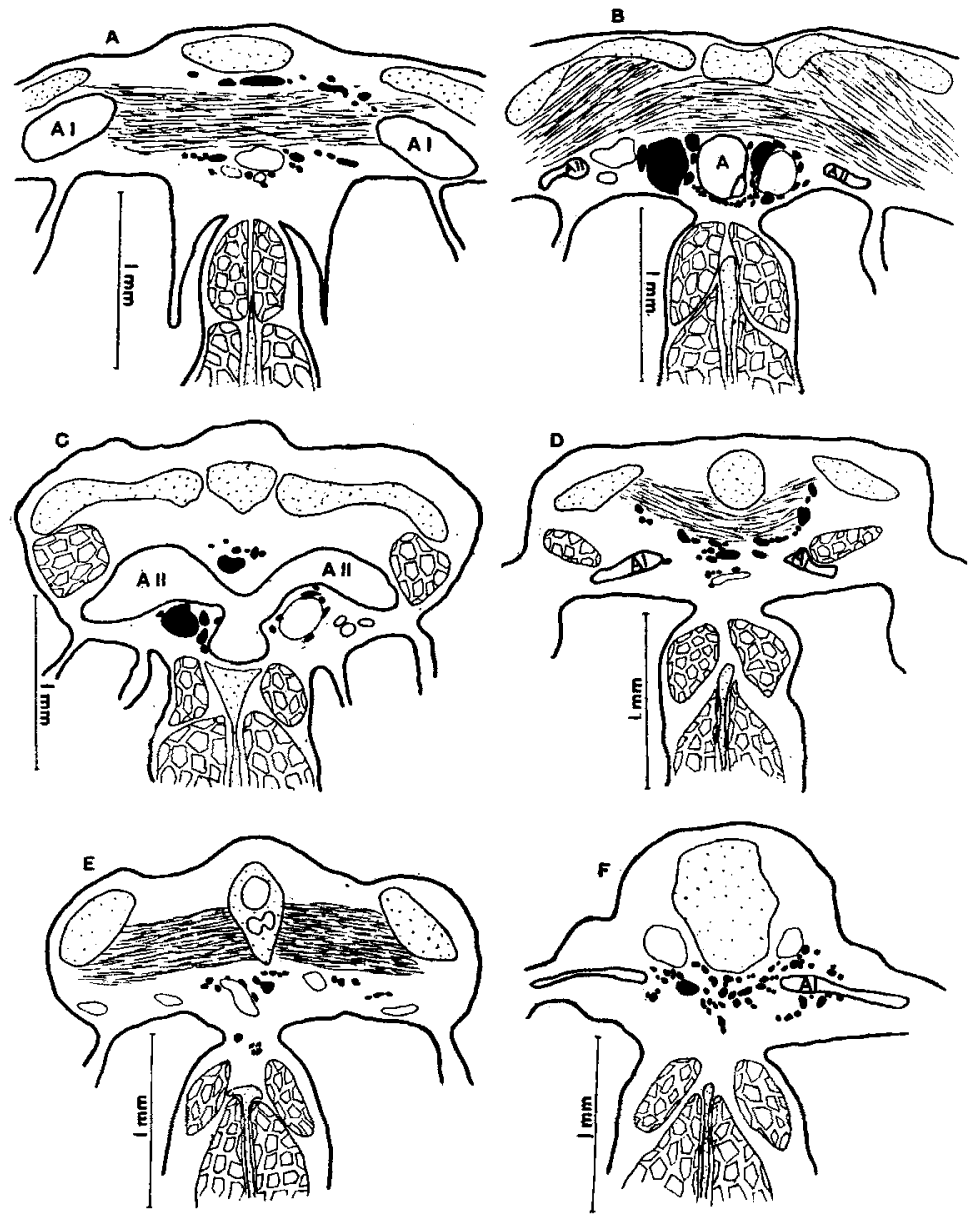

Fig. 10. Sections through the thyreoid gland of Fundulus. $A$ to $C, F$. heteroclitus. $A$, in the aortic bifurcation; $B$, anterior to; $C$, at the second branchial arteries. $D, F$. diaphanus, in the aortic bifurcation. $E$ and $F, F$. majalis, anterior to the aortic bifurcation.

the capillaries show narrower and longer cells, and some of these cells entirely lose their communication with the follicular lumen. The connective tissue sometimes forms an almost complete sheath around the follicles and their capillaries. Red blood corpuscles in all stages of disintegration are found in many follicles 
(seeGeneral Part). How these corpuscles get into the lumen could not be determined. Erythrocytes are often seen partially imbedded in the follicular epithelium as if they would force their way in between two cells. In other places corpuscles are found pressed against an epithelial cell which has so flattened out that only a thin layer of cytoplasm separates the corpuscle from the lumen.

\section{FUNDULUS DIAPHANUS LE SUEUR}

A specimen $9 \mathrm{~cm}$. long. The main mass of the thyreoid is located a little nearer the tip of the tongue than in F. heteroclitus (pl. I, fig. 7). The posterior end lies at the second branchial arteries where the follicles become scarce and scattered. A further difference from heteroclitus is that the main mass of follicles always lies above the aortic stem, only a few small ones lying below. The lateral extension is here also unimportant.

The floor of the pharynx is narrow and the connection between it and the ventral musculature is only a narrow streak. In heteroclitus the lateral pharyngeal axis is the longer one, therefore, the lateral thyreoid extension prevails; while in diaphanus the dorso-ventral axis is longer, and here the extension of the thyreoid is mainly in this direction. Ventrally, however, it is prevented by the narrow isthmus, and follicles are mainly found above the aorta (fig. 10, D). In this way the distribution of the follicles may be figured out mechanically in almost every case.

The follicles are of all sizes, though not so large as in heteroclitus. There are more elliptical or irregular ones and these have a longer axis. The cuboidal cells of the follicular epithelium are not as high as in heteroclitus and cylindrical ones are not found. The colloid is homogeneous and the blood supply is not rich.

\section{FUNDULUS MAJALIS WALBAUM}

Length of specimen $9 \mathrm{~cm}$. The follicles spread out laterally much further than in the other two species (fig. 10, $E, F$ ). They extend for a distance along the first aortic branches. Between the first and second branches there is only a narrow streak of thyreoid 
tissue, but the main mass of the organ lies at the second gill branches and here the greatest lateral extension occurs under a transverse muscle. The vertical extension is small and there are no follicles below the aorta. Behind the second gill branches is found the posterior limit of the gland (pl. I, fig. 8).

The follicles are still smaller than in diaphanus and more uniform in size. The circular type predominates and they are more numerous than in the other species. The colloid is homogeneous and the follicular epithelium similar to that in diaphanus.

\section{MENIDIA NOTATA MITCHILL}

Length of specimen $10 \mathrm{~cm}$. The thyreoid mass is rather small (pl. I, fig. 9). The follicles are extremely small, $20-25 \mu$, and are scattered along the stem of the aorta between the first and second branchial arteries and out along the second arteries. The lateral extension is greater than the antero-posterior.

\section{MUGIL CEPHALUS L.}

A mullet $15 \mathrm{~cm}$. long. Small follicles are found in the anterior end of the thyreoid region and are grouped around a vein (fig. 11, $A$ ). At the aortic bifurcation the organ is better developed, but is hardly in contact with the gill vessels (fig. 11, B). The thyreoid lies above the aorta, and at the second branchial arteries it comes into contact with the vessel. Here the gland is well developed with numerous large follicles. The follicles disappear towards the third aortic branches (pl. I, fig. 13).

The size of the follicles varies between 30 and $140 \mu$. In section they are slightly oval. In the follicular wall are found transitions from flat to high epithelium. The height of the cells varies within the same follicle, showing that it is independent of follicle size. The height of the cells rather depends upon outside pressure, e.g., a follicle pressed into oval shape by cartilage shows low epithelium on the longer sides and higher cells on the short sides. 


\section{SARDA SARDA BLOCH}

Length of specimen $50 \mathrm{~cm}$. The thyreoid gland of the Spanish mackerel shows the most remarkableconditions of all fish thyreoids.

The mass of the organ is enormously large and the dorso-ventral and cephalo-caudad extensions are unusual. The relation of the thyreoid gland to other tissue is singular, and could be compared only with that in Brevoortia. There exists such an intermingling of thyreoid, bone, cartilage, smooth and striated muscle fibres, fat and connective tissue that it is impossible sharply to define
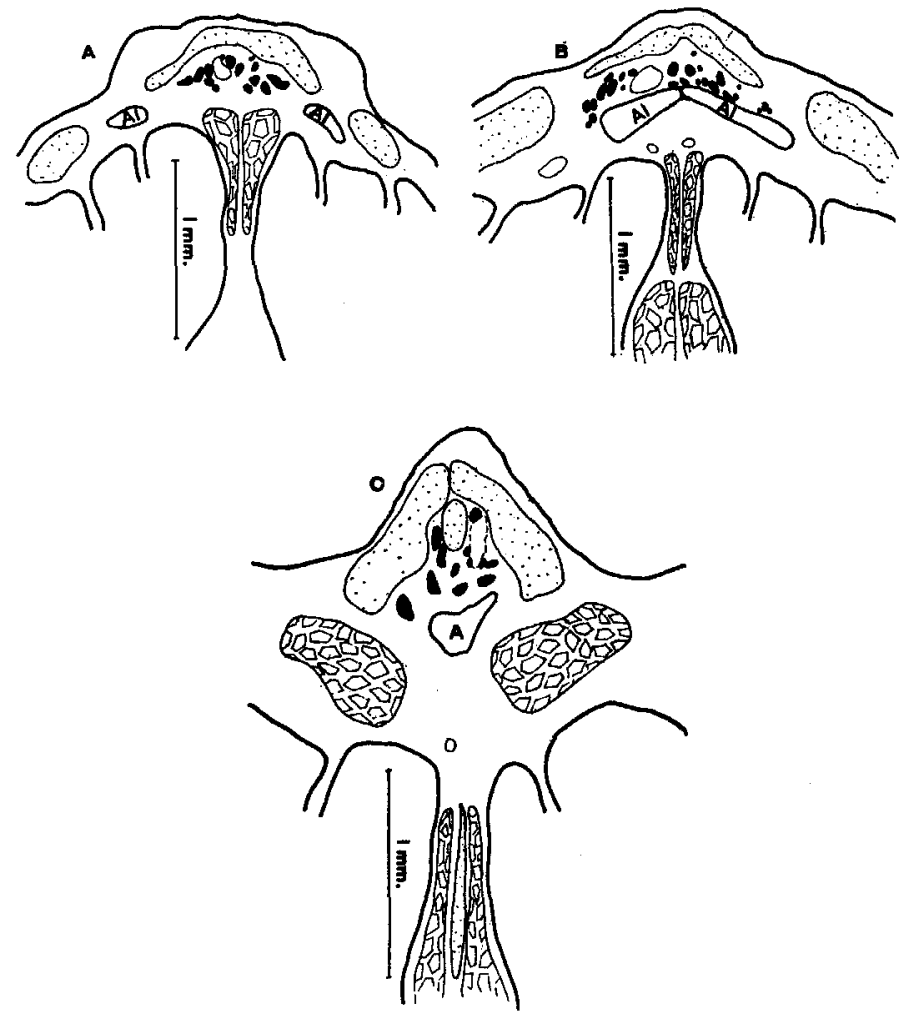

Fig. 11. Sections through the thyreoid gland of Mugil. $A$, anterior to; $B$, at the aortic bifurcation; $C$, near the second branchial arteries. 
the organ. Yet on the other hand, there can hardly be found a group of follicles detached from the main thyreoid body.

The isthmus is long, as in Brevoortia, and hence the thyreoid region is much elongated (pl. I, fig. 10), measuring $4 \mathrm{~cm}$. in length. It is not, however, as narrow as in the menhaden, having a wide lateral extension. The anterior end is pushed far forward, $2.5 \mathrm{~cm}$. in front of the aortic bifurcation, so that it also comes to lie in front of the hyoid arch. The entire development of the organ takes place more cephalad than usual and the main mass lies in front of the aortic bifurcation (sharks!), deeply buried in the body of the tongue, as a consequence of the ventral extension of the copulohyoid (fig. 12, $A$ ). It occupies a more ventral position than any other fish thyrecid. The follicles are located around a large vein and are rather closely arranged. As the basi- and hypohyalia retract the follicles creep into the clefts between them and thus the thyreoid mass assumes the shape of a horse-shoe, the two arms of which point dorsally (fig. 12, $B, C$ ). The smooth muscle fibres of this region are completely invaded by follicles (pl. IV, fig. 21), as are also the bones of the gill arch, especially the copula, in regions where they lose their compactness and break up into lamellae. The thyreoid takes the form of three masses converging ventrally, and as we pass back it expands more and more on the sides, 6 to $7 \mathrm{~mm}$., while the median branch becomes smaller. About one $\mathrm{cm}$. in front of the aortic bifurcation the most extensive region of the gland is reached. In cross section the mass is rhomboidal, the diagonals being about 7 and $4 \mathrm{~mm}$. The lateral extension decreases while the ventro-median mass increases, from which two branches tend dorsally along the edge of the copula. Thus again the sections show a horse-shoe shape, with a broad middle piece and narrow dorsally converging arms, in which the follicles are oval with their longer axis parallel to the line of extension. On reaching the first branchial arteries, which run in this species towards a ventro-lateral zone and do not come into contact with the follicles (fig. 12,C) we pass to their union where a few follicles surround them (fig. 12,D). The central portion of the gland becomes smaller and lies separate in the aortic bifureation while 

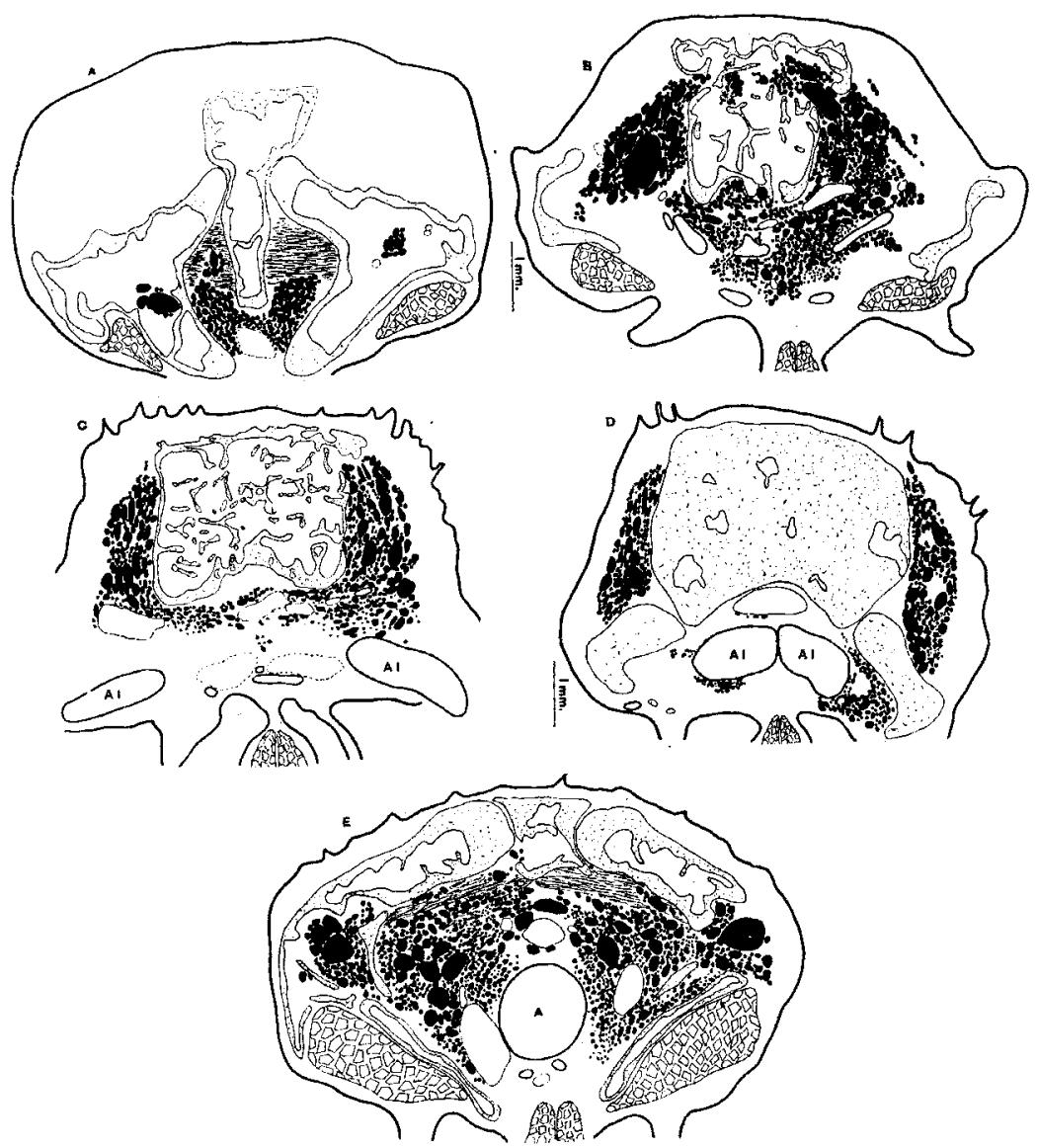

Fig. 12. Sections through the thyreoid gland of Sarda. A, near the anterior end of the gland; $B$, in the region of greatest extension anterior to the aortic bifurcation; $C$ and $D$, close to the aortic bifurcation; $E$, near the second branchial arteries, the region of greatest extension.

the lateral parts increase posteriorly. Thus in the sections there are three portions of thyreoid which become more and more separated by the enlargement of the copula (fig. 12, D). Behind the aortic bifurcation some follicles appear below the aorta; the middle mass again enlarges and the three parts unite. One branch again extends into the copula and soon becomes smaller, while the lateral 
portions increase. The posterior end of the gland is found behind the second gill branches.

The follicles are usually circular or oval in cross sections, though many are polygonal from pressure. Their size varies between 30 and $350 \mu$ medium sizes being most abundant. Giant follicles reach $800 \mu$ long by $400 \mu$ in short diameter. Many follicles are without colloid, while in others the colloid is much more shrunken than usual. The colloid is homogeneous. The follicular epithelium is of high cylindrical cells or cubical ones. The cytoplasm is stained more darkly in the basal portions; in the higher parts it is sometimes reddish. The blood supply is rich.
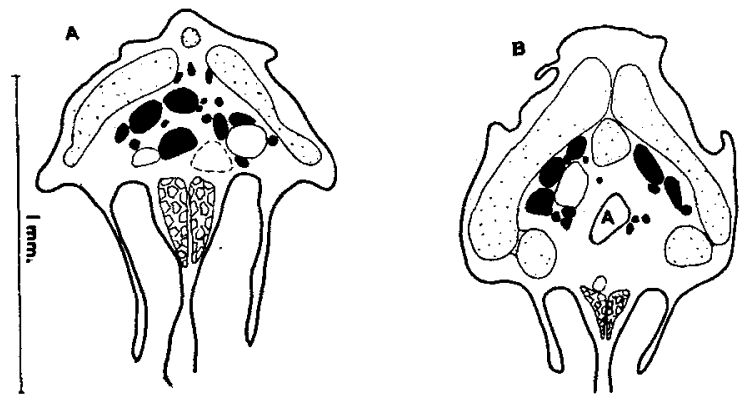

Fig. 13. Sections through the thyreoid gland of Pomatomus. $A$, anterior to the aortic bifurcation; $B$, between the second and third branchial arteries.

\section{POMATOMUS SALTATRIX L.}

Young bluefish $30 \mathrm{~cm}$. long. In this species the dispersion of the thyreoid follicles is prevented in both a lateral and dorso-ventral direction, since the arch formed by the basibranchiale and hypobranchialia is very narrow (fig. 13). The gland is thus a long narrow streak (pl. I, fig. 11). At the aortic bifurcation there are only a few follicles, some of which lie close to the first gill arteries, just in front of their point of union. The thyreoid mass reaches its maximum extension above the ventral aorta and between the first and second gill arteries, especially towards the second. But 
even here there are only ten or fifteen follicles in a cross section. Some follicles lie close to the base of the second gill arteries and from this point the gland extends, with from six to ten follicles in a cross section, to a little behind the third branchial arteries where it ends. The follicles are generally dorsal to the ventral aorta (fig. 13, $B$ ), only a few being below it.

The form of the follicles is irregular, but approaches the globular type. Their size ranges from $15-100 \mu$ in diameter though some are far above this size (giant follicles). The minute histology shows no peculiarities. The epithelium is usually cubical, the cells being $6 \mu$ high.

\section{MORONE AMERICAN'A GMELIN}

Specimen $35 \mathrm{~cm}$. in length. The thyreoid gland of the white perch is characterized by the enormous size of nearly all the follicles as well as by their unusually loose arrangement. Cephalad of the aortic bifurcation there is little room for dispersion since the copula reaches far down and the skeletal arch is rather narrow. Behind the bifurcation (fig. 14, B) this arch becomes wider and from here to the second gill arteries the main mass of the thyreoid is situated (pl. I, fig. 12). From the second branchial arch towards the third two narrow lines of follicles run along the sides of the aorta. The entire length of the thyreoid region measures $3.5 \mathrm{~cm}$. The majority of the follicles lie above the aorta except in the anterior region.

The size of the follicles varies from 120 to $600 \mu$ in diameter, the very large ones are most abundant especially in the more anterior region. In cross sections the follicles are almost all circular. The epithelial cells are low, 3 to $4 \mu$ high. In these follicles there are no indentations in the colloid, it either fills out the lumen completely or is retracted from the epithelium and has a smooth edge. (The differences in the colloid of different species may be of some physiological significance.) 

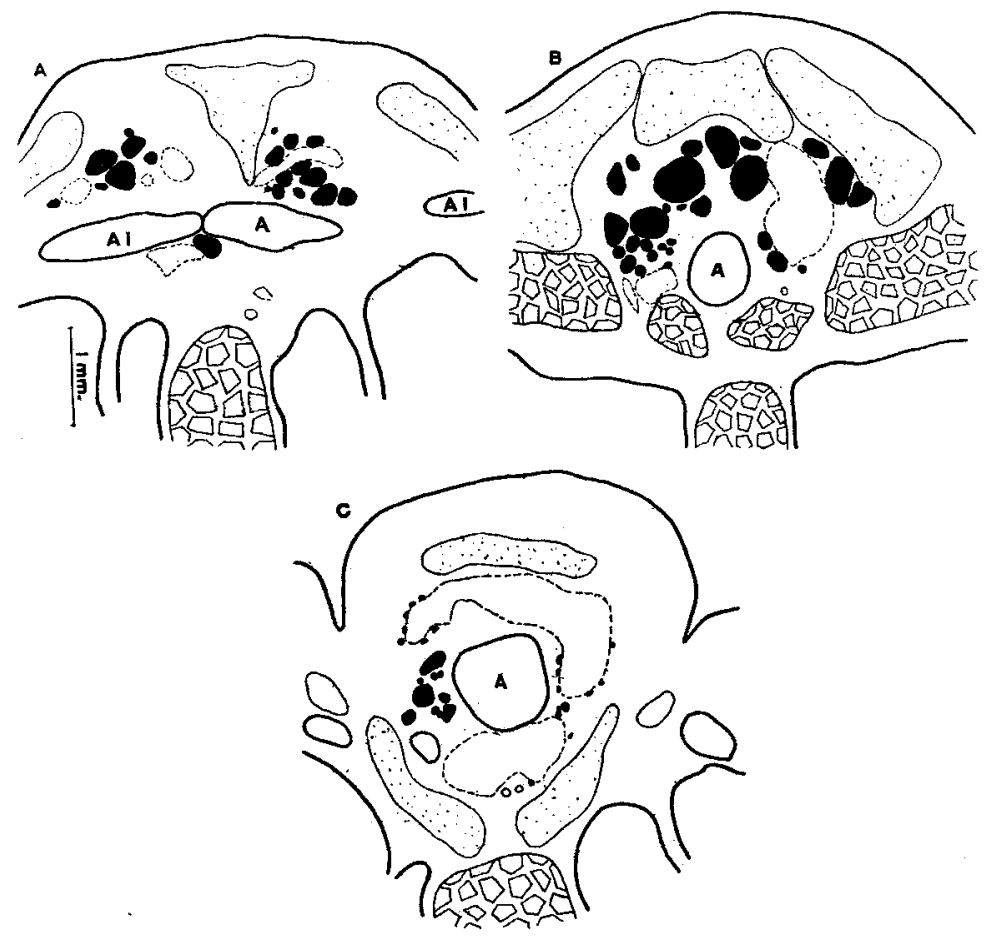

Fig. 14. Section through the thyreoid gland of Morone. $A$, at the aortic bifurcation; $B$, between first and second; $C$, close to the second branchial arteries.
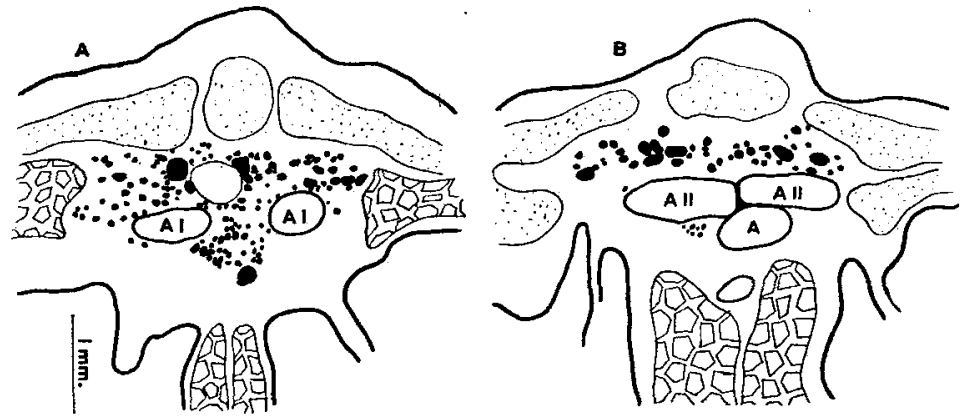

Fig. 15. Sections through the thyreoid gland of Stenotomus. $A$, in the aortic bifurcation; $B$, at the second branchial arteries. 
Length of specimen $25 \mathrm{~cm}$. The scup presents the thyreoid gland as a rather continuous organ, only one group of follicles lying below the aorta is isolated from the main mass. The largest expansion of the gland is in (fig. 15, A) and immediately behind the aortic bifurcation; here it measures $3 \mathrm{~mm}$. in width, and dorsoventrally over $1 \mathrm{~mm}$. This expansion is followed by a restriction, the follicles always lying above the aorta. At the second branchial arches another increase in the thyreoid tissue occurs, and here a few follicles appear below the aorta (pl. I, fig. 14).

The size of the generally circular follicles varies from 20 to $300 \mu$ in diameter, a few reaching $400 \mu$.

\section{CYNOSCION REGALIS BLOCH}

Specimens of $60 \mathrm{~cm}$. in average length. Twelve specimens of the squeteague were examined and they serve to show a series of variations in the thyreoid gland within the species. The region of the gland extends from in front of the aortic bifurcation to the third branchial arteries. The majority of follicles always lie either dorsal or lateral to the aortic stem and in only two cases were any follicles found below the aorta. In one case the aortic stem between the first and second branches was surrounded. The region of the second aortic branches is commonly filled by the gland. The tendency to extend from this place anteriorly is more often expressed than in the opposite direction. The lateral extension is greater along the branchial arteries than in intermediate regions (pl. III, figs. 31-41).

In some of the specimens there were two (pl. III, figs. 33, 36, 37,40 ) or even three and four (pl. III, fig. 34) well developed isolated portions of the gland lying on different branches of the gill vessels. Macroscopically they appear to be separated, but on tracing the entire region in serial sections it is found that follicles spread out and connect the several masses, although the follicles are small and scattered so thinly that they were not seen with the naked eye. 

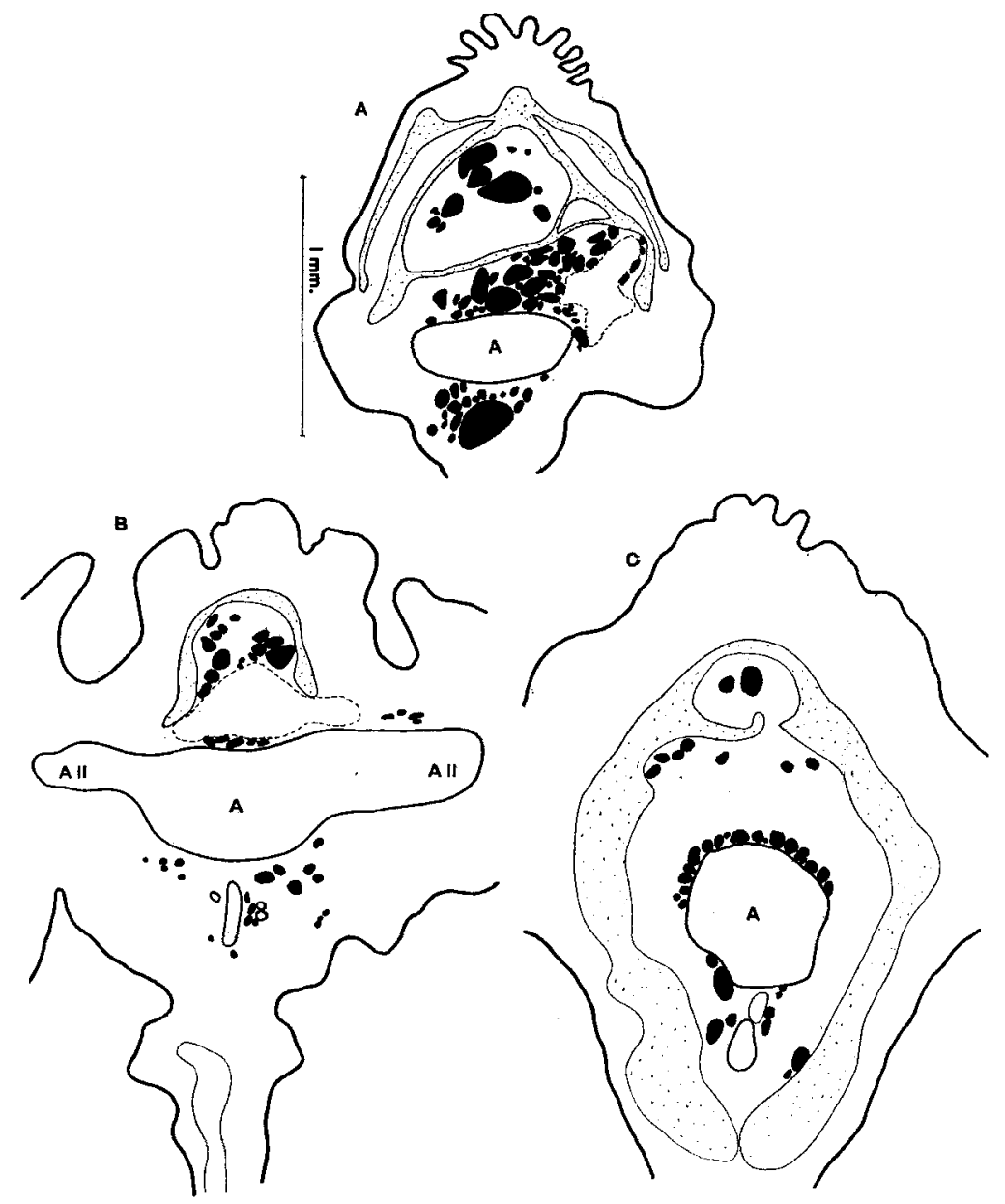

Fig. 16. Sections through the thyreoid gland of Micropogon. $A$, between the first and second; $B$, at the second; $C$, near the third branchial arteries.

The mass of thyreoid tissue, roughly judging, differed in the specimens, although they were of about the same size, yet the fish may have been of different ages.

The shape of the follicles varies from very irregular to circular. Their size also varies extremely. Those lying nearest the vessels are huge and irregular, while the small peripheral ones approach 
a globular shape. This indicates that the shape of the follicles is a result of the pressure directions. The follicular arrangement is rather compact in the central portions. (pl. V, fig. 17.)

The epithelial cells vary from low cuboidal to high cylindrical shapes. The smaller follicles seem to have a little higher epithelium, though it is rather uniform in the same individual and varies more among the several specimens. It may seem therefore that the entire gland is in the same physiological stage.

\section{MICROPOGON UNDULATUS L.}

A croaker, $30 \mathrm{~cm}$. long. The thyreoid extends from the first to the third branchial arteries (pl. II, fig. 15). The dispersion of follicles is largely dorso-ventral, since laterally they are hindered by the narrowness of the isthmus (fig. 16, $A, C$ ). For this reason also a considerable part of the gland lies below the aorta, yet not so large a portion as above, though the dorsal follicles are less densely arranged.

There are only a few follicles in front of the aortic bifurcation, yet at the bifurcation and behind it lies the main mass of the gland. The follicles completely fill the spaces between bones and vessels (fig. 16, A). Towards the second gill branches the copula extends further and further down and forces the follicles into a somewhat lateral position. The ventral mass is larger in this region. At the second arterial branches there is no special increase in mass, the number of ventral follicles having decreased (fig. 16, B), the dorsal ones increasing and soon extending to the epithelium of the pharyngeal floor. The follicles lie rather loosely arranged, but have not noticeably increased in size. A small line of follicles above the aorta extends from here towards the third gill branches, others are scattered irregularly around the aorta. The aorta has sunk into the ventral muscle and carries the posterior follicles with it.

The thyreoid gland of Micropogon is characterized by rather small follicles of almost uniform size, though in some regions large ones appear. The diameters range from 10 to $300_{\mu}$, but those of 30 to $50 \mu$ are most abundant. 
The epithelium is rather low, even in the smallest follicles. Branched follicles are numerous. The blood supply is rich, many capillaries being present around the follicles. There are several larger veins running through the thyreoid region.

\section{TAUTOGOLABRUS ADSPERSUS WALBAUM}

Length of specimen $25 \mathrm{~cm}$. In the cunner the thyreoid gland occupies a unique position, almost resembling that in the sharks. It is pushed far forward in the aortic bifurcation, and touches both the first branchial arteries laterally (fig. 17, B), but does not extend far enough back to come into contact with the ventral aorta (pl. II, fig. 16). The main mass is, as it were, imbedded in a bony capsule. The follicles are grouped around a median vein (fig. 17, A). Dorsal to the aortic bifurcation the copula and a transverse muscle are well developed, so that the thyreoid is forced forward. The follicles are not numerous, and are all more or less irregular. Their diameters measure from 15 to $200 \mu$. The follicular epithelium is cuboidal.

\section{TAUTOGA ONITIS L.}

Specimen $35 \mathrm{~cm}$. long. In the closely related tautog the thyreoid gland also occupies a rather cephalad position (pl. II, fig. 17). It extends back from within the aortic bifurcation almost to the second branchial arteries. It lies chiefly above and to the sides of the aorta. The anterior, main part, is imbedded in an osseous capsule which is square in cross section, and is formed by three branchial bones above and a ventral supporting bone (fig. 18, $A$ ). At the aortic bifurcation the capsule becomes incomplete and the follicles are widely dispersed over $6 \mathrm{~mm}$. (fig. 18, $B$ ). The follicles follow the dorsal side of the first arterial branches out to the base of the gills. Behind the first branchial arteries the lateral extension decreases and the follicular dispersion is in a dorso-ventral direction. The follicles are loosely arranged, and yet globular ones are rare, most of them being polygonal in outline. The average size is $150 \mu$ in diameter, but there are a few giant folli- 

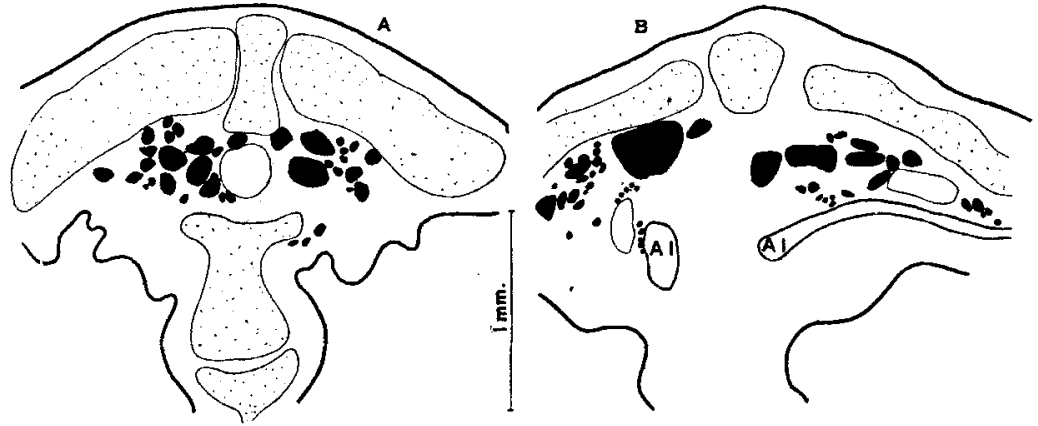

Fig. 17. Sections through the thyreoid gland of Tautogolabrus. $A$ and $B$, anterior to the aortic bifurcation.
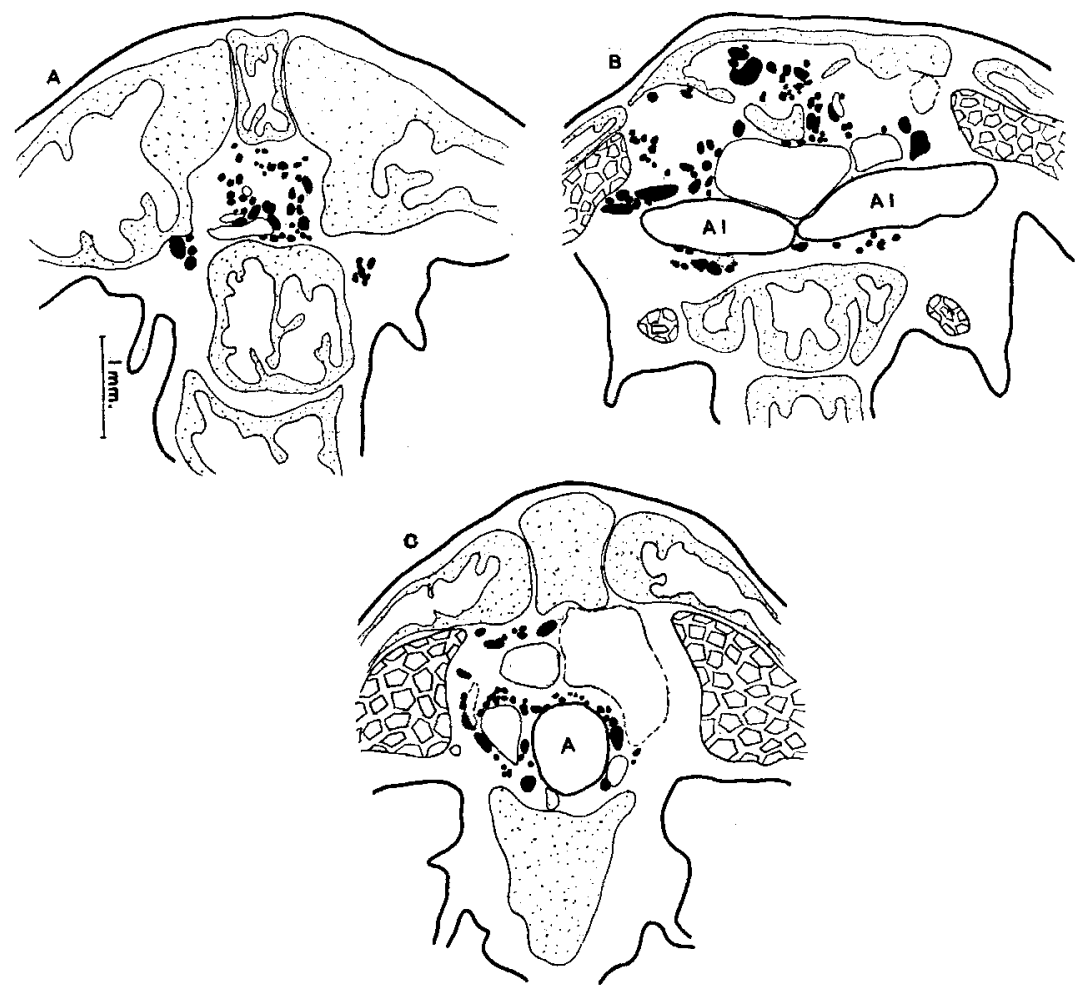

Fig. 18. Sections through the thyreoid gland of Tautoga. A, anterior to; $B$, at and $C$, posterior to the aortic bifurcation. 
cles, $700 \mu$ long by $400 \mu$ broad. Branched follicles are numerous. The epithelial cells are cuboidal in shape.

\section{PRIONOTUS CAROLINUS BLOCH}

In a sea-robin $30 \mathrm{~cm}$. long the thyreoid gland seemed to show a pathological appearance. The invasion of the surrounding tissues by thyreoid follicles was extraordinary, but may be abnormal. For this reason it can only be stated that the gland in this species occupies a posterior position, close to the origin of the truncus arteriosus.

OPSANUS TAU L.

A toadfisi $30 \mathrm{~cm}$. long the gill region in this species is extremely shortened, and therefore the thyreoid region begins rather far forwards. Anteriorly the largest follicles lie on both sides of a process of the copula which extends ventrally (fig. 19, $A$ ). Towards the aortic bifurcation the size of the follicles decreases and the two lateral portions unite in the median line, at the same time the lateral extension (fig. 19, $B$ ) of the follicles increases remarkably (pl. II, fig. 18). Some follicles appear below the aortic stem. Between the first and second branchial arches the number of follicles decreases above the aorta, while ventrally they disappear entirely. Along the second branchial arteries the follicles again reach laterally and also again appear ventrally. Behind this point the aorta sinks more and more and the space around it becomes freer. Yet there is no special increase of thyroid tissue in this region, there being only loosely scattered small follicles. A few follicles accompany the aorta in its course into the space between the musculus sternohyoideus. The caudal end of the thyreoid lies behind the third gill branches.

The arrangement of the follicles is loose, and they are usually circular in cross sections. Some are flattened between the bony and muscular surrounding tissues. Their size varies extremely. The largest ones, $600 \mu$ in diameter, lie in the anterior end, which is the reverse of the general rule for other species. In other regions 
the follicular diameters vary from $50-400 \mu$, the median size follicles being the most abundant.

The follicular epithelium is always cuboidal. Colloid is present in almost all the follicles, and is very brittle and homogeneous. In the larger follicles the colloid stains much lighter than in the
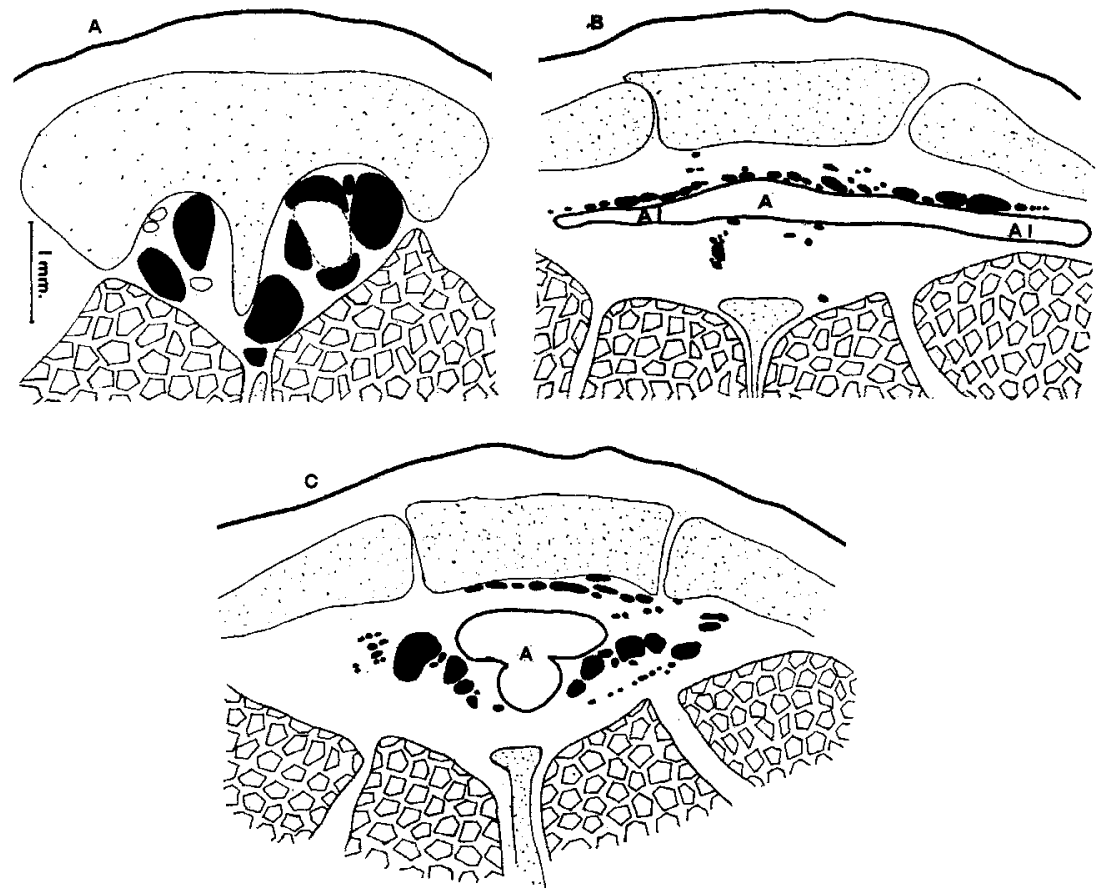

Fig. 19. Sections through the thyreoid gland of Opsanus. $A$, anterior to; $B$, at the aortic bifureation; $C$, at the second branchial arteries.

smaller. Lymphocytes are numerous within the follicles. The blood supply of the thyreoid region is very poor.

\section{MURAENOIDES GUNELLUS L.}

Length of specimen $40 \mathrm{~cm}$. The thyreoid gland in the butterfish reaches a considerable size (pl. II, fig. 19). The anterior end lies in front of the aortic bifurcation and consists only of small 

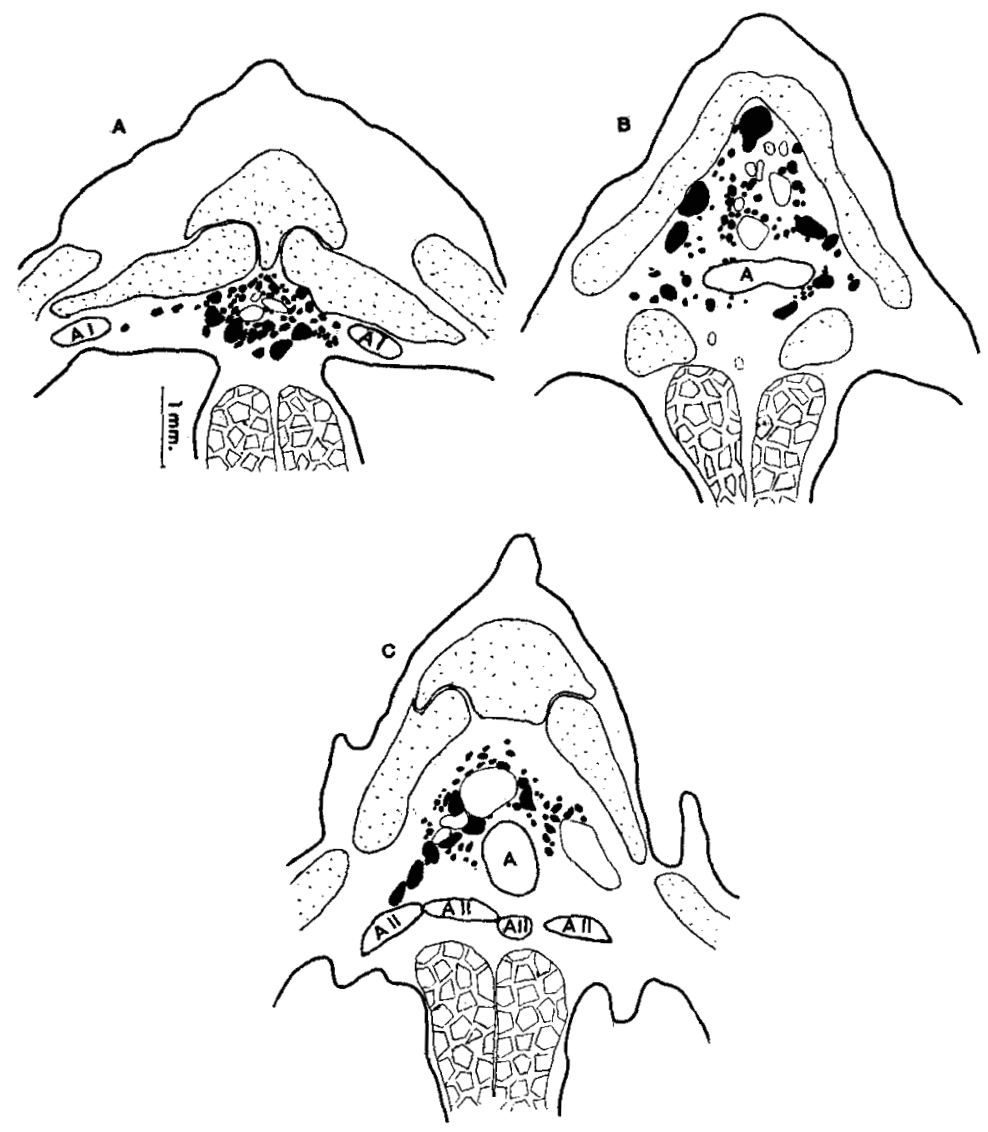

Fig. 20. Sections through the thyreoid gland of Muraenoides. $A$, anterior to the aortic bifurcation; $B$, between the first and second; $C$, close to the second branchial arteries.

scattered follicles. In the middle portion of the gland the follicles are numerous and closely arranged. At the aortic bifurcation they lie around a large vein and completely fill out the space between the gill arch and muscles. The lateral extension of the follicles is small as compared with the dorso-ventral, since the isthmus is narrow (fig. 20, $B$ ). A cross section through the thyrcoid area measures about $1 \mathrm{~mm}$. Taking $1 \mathrm{~mm}$. as the average. width we would have 10 cubic mm. of thyreoid tissue in this specier. 


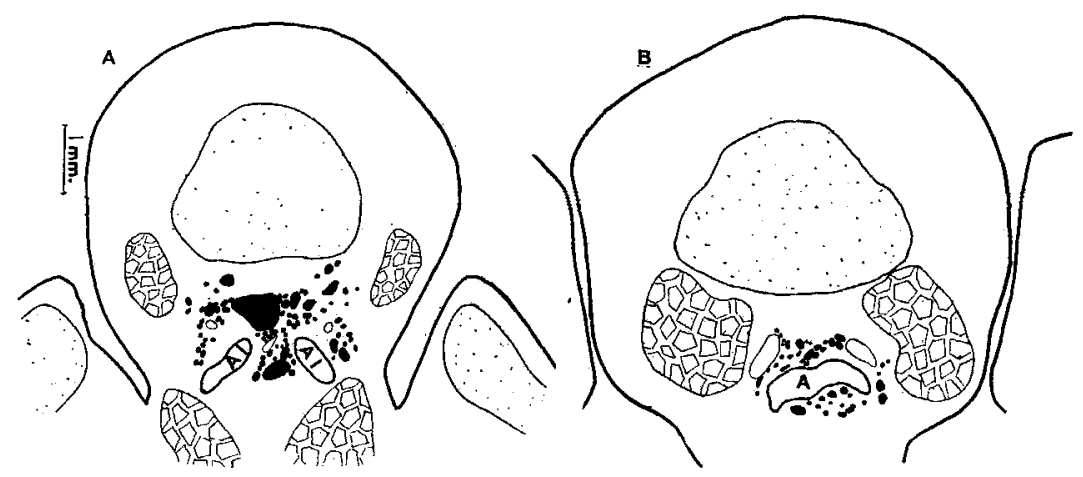

Fig. 21. Sections through the thyreoid gland of Pleuronectes. $A$, in the aortic bifurcation; $B$, just posterior to it.

The first branchial arteries are partly surrounded by follicles. Behind the aortic bifurcation there is an open space for lateral extension, but not for ventral, since the aorta rests on the musculature. The caudal end of the gland lies a little behind the second branchial arteries, and consists again of small scattered follicles (fig. 20,C).

The follicles are of globular or long ovoid shape, some are very irregular. The circular cross sections vary from 20 to $500 \mu$ in diameter. The very large ones lie at the second arterial branches. Branched follicles with connecting channels between them are numerous, so that almost all follicles may be traced in sections as evaginations of others.

The follicular epithelial cells vary from highly cylindrical, narrow shapes to broad cuboidal. Flattened epithelium is rare. The cells are extremely numerous and densely arranged. The nuclei are located near the base of the cells, even in the higher ones, and the cytoplasm stains darker about the nucleus. Sometimes it appears as if there were a cuticle on top of the cells, as many authors have described. This, however, is nothing else than a refractive appearance of the cell margin from which the cytoplasm has slightly retracted. The blood supply is extremely rich.

(A parasitic worm was found in this thyreoid and had caused a considerable hemorrhage.) 
Length of specimen $45 \mathrm{~cm}$. The position of the thyreoid gland in the flounder varies (pl. III, figs. 30,31). In one case it formed a rather compact nodule between the first and second branchial arteries, while in another the main mass was found in the aortic bifurcation between and surrounding the first branchial branches (fig. 20, A). Behind the aortic bifurcation there were only smaller follicles dorsal and lateral to the aorta. The broad base of the deep reaching copula permits only a lateral extension; thus the thyreoid presents itself as a transverse streak. Small detached follicles lie close to the base of the gills.

The size of the follicles varies from 15 to $1000 \mu$ in diameter, those of about $200 \mu$ being in the majority. There are also a few 'giant' follicles. The epithelial cells of the follicles are closely arranged and rather high. The nuclei are oval. The blood supply is rich and lymphatic vessels are well developed. 


\section{BIBLIOGRAPHY}

Anderson, O. A. 1894 Zur Kenntnis der Morphologie der Schilddrüse. Arch.f. Anat. u. Phys., Anat. Abt., 177.

BABER, S. C. 1876 Contributions to the minute anatomy of the thyroid gland of the dog. Phil. Trans. R. Soc., London, 166, Part 2, 557.

1881 Researches on the minute structure of the thyroid gland, Phil. Trans. R. Soc., London, 172, 577.

Bó́chat, P. A. 1873 Recherches sur la structure normale des corps thyroïde. Paris.

Borces, J. 1907 Observations sur la musculature branchiostégale des Teleostéens. Ann. Sc. Univ. Jassy, 4, 203.

Cole, F. J. 1905 Notes on Myxine. Anat. Anz., 27, 324.

CorI, C. J. 1906 Das Blutgefässytem des jungen Ammocoetes. Arb. Zool. Jnst. Wien, 16, 217.

Dorrn, A. 1885 Studien zur Urgeschichte der Wirbeltiere, Mitt. Zool. Stat. Neapel.

ERDHEIM, J. 1903 Zur normalen und pathologischen Histologie der Glandula thyreoidea, Parathyreoidea und Hypophysis. Ziegler's Beitr. z. path. Anat. u. allg. Path., 33, 158.

FERGUSON, J. S. 1911 The anatomy of the thyreoid gland of Elasmobranchs with remarks upon the hypobranchial circulation in these fishes. Am. Jour. Anat., Vol. 11, No. 2.

Fonsyth, D. 1908 The comparative anatomy, gross and minute, of the thyroid and parathyroid glands in mammals and birds. J. Anat. and Phys., $42,141,302$.

Galeotti, G. 1897 Beitrag zur Kenntnis der Secretionserscheinungen in den Epithelzellen der Schilddrüse. Arch. f. mikr. Anat., 48, 305.

Greil. 1906 Ueber die Entstehung der Kiemendarmderivate von Ceratodus F. Verh. Anat. Ges., 20. Vers., 115.

Gudernatsch, J. F. 1909 The structure, distribution and variation of the thyreoid gland in fish. Am. Ass. Cancer Research, Nov, 27, 1909. (J. Am. Med. Ass., 54, 227.)

HÜRThLE, K. 1894 Beiträge zur Kenntnis der Secretionsvorgänge in der Schilddrüse. Arch. f. d. ges. Physiol. 65, 1.

Jordan and Evermann. 1906-'00 The fishes of North and Middle America.

Kölliker, A. 1861 Entwicklungsgeschichte d. Menschen u. d. höheren Tiere, Leipzig.

Langendorf, O. 1889 Beiträge zur Kenntnis der Schilddrüse. Arch. f. d. ges. Physiol., Suppl., 219. 
LIVINI. 1902 Organi del sistema timo-tiroideo nella Salamandrina perspicillata. Arch. It. Anat. Embr., Firenze, 1, 1.

Marcus, H. 1908 Beiträge zur Kenntnis der Gymnophionen. I. Ueber das Schlundspaltengebiet. Arch. f. mikr. Anat., 71, 695.

Marshald, C.F. 1895 Variation in the form of the thyroid gland in man. Jour. Anat. and Phys., 29, 234.

Maurer, Fr. 1886 Schilddrüse und Thymus der Teleostier. Morph. Jahrb., $11,129$.

1888 Schilddrüse, Thymus und Kiemenreste bei Amphibien. Morph. Jahrb., 13, 296.

MǗlier, L. T. 1896 Beiträge zur Histologie der normalen und der erkrankten Schilddrüse. Ziegler's Beiträge z. path. Anat. u. allg. Path., 19, 127.

MứlLER, W. 1871 Ueber die erste Anlage der Schilddrüse und deren Lagebeziehung zur ersten Anlage des Herzens bei Amphibien, insbesonders bei Triton alpestris. Anat. Hefte, 26, 1.

Muthmann, E. 1904 Ueber die erste Anlage der Schilddrüse. Anat. Hefte, 26, 1.

Peremeschko. 1867 Ein Beitrag zum Bau der Schilddrüse. Zeitschr. f. wiss. Zool., 17, 279.

Platt, J. 1896. The development of the thyroid gland and of the suprapericardial bodies in Necturus. Anat. Anz., 11.

Schafrer, J. 1906 Berichtigung, die Schilddrüse von Myxine betreffend. Anat. Anz., 28, 65 .

Schmid, E. 1896 Der Secretionsvorgang in der Schilddrüse. Arch. f. mikr. Anat., 47, 181.

Silvester, C. F. 1905 The blood-vascular system of the tile-fish, Lopholatilus chamaeleonticeps. Bull. Bur. Fish. Washington, 24, 87.

Simon, J. 1844 On the comparative anatomy of the thyroid gland. Phil. Trans. R. Soc., London, 134, 295.

Stockard, Ch. R. 1906 The development of the thyroid gland in Bdellostoma stouti. Anat. Anz., 29, 91.

Streckeisen, A. 1886 Beiträge zur Morphologie der Schildrüse. Virchow's Arch. f. path. Anat., 103, 131, 215. 
PLATES 
Plates I and II show the regions of distribution of the thyreoid elements in different species. I, aortic bifurcation or first branchial arteries; II, III and IV, the second, third and fourth branchial arteries.

1 Anguilla chrysypa

2 Clupea harengus

3 Brevoortia tyrannus

4 Osmerus mordax

5 Siphostoma fuscum

6 Fundulus heteroclitus

7 Fundulus diaphanus

8 Fundulus majalis

9 Menidia notata

10 Sarda sarda

11 Pomatomus saltatrix

12 Morone americana

13 Mugil cephalus
14 Stenotomus chrysops

15 Micropogon undulatus

16 Tautogolabrus adspersus

17 Tautoga onitis

18 Opsanus tau

19 Muraenoides gunellus

20 Oncorhynchus kisutch

21 Salmo mykiss

22 Salmo irideus, age 1 month

23 Salmo irideus, age 1 year

24 Cristivomer namaycush

25-27 Salvelinus fontinalis

Plate III, Diagrams of actual portions of the thyreoid gland visible to the naked eye.

28 and 29 Salvelinus fontinalis

30 and 31 Pseudopleuronectes americanus

32-41. Ten specimens of Cynoseion regalis, demonstrating the great variability in extent and position of the organ within the species. 

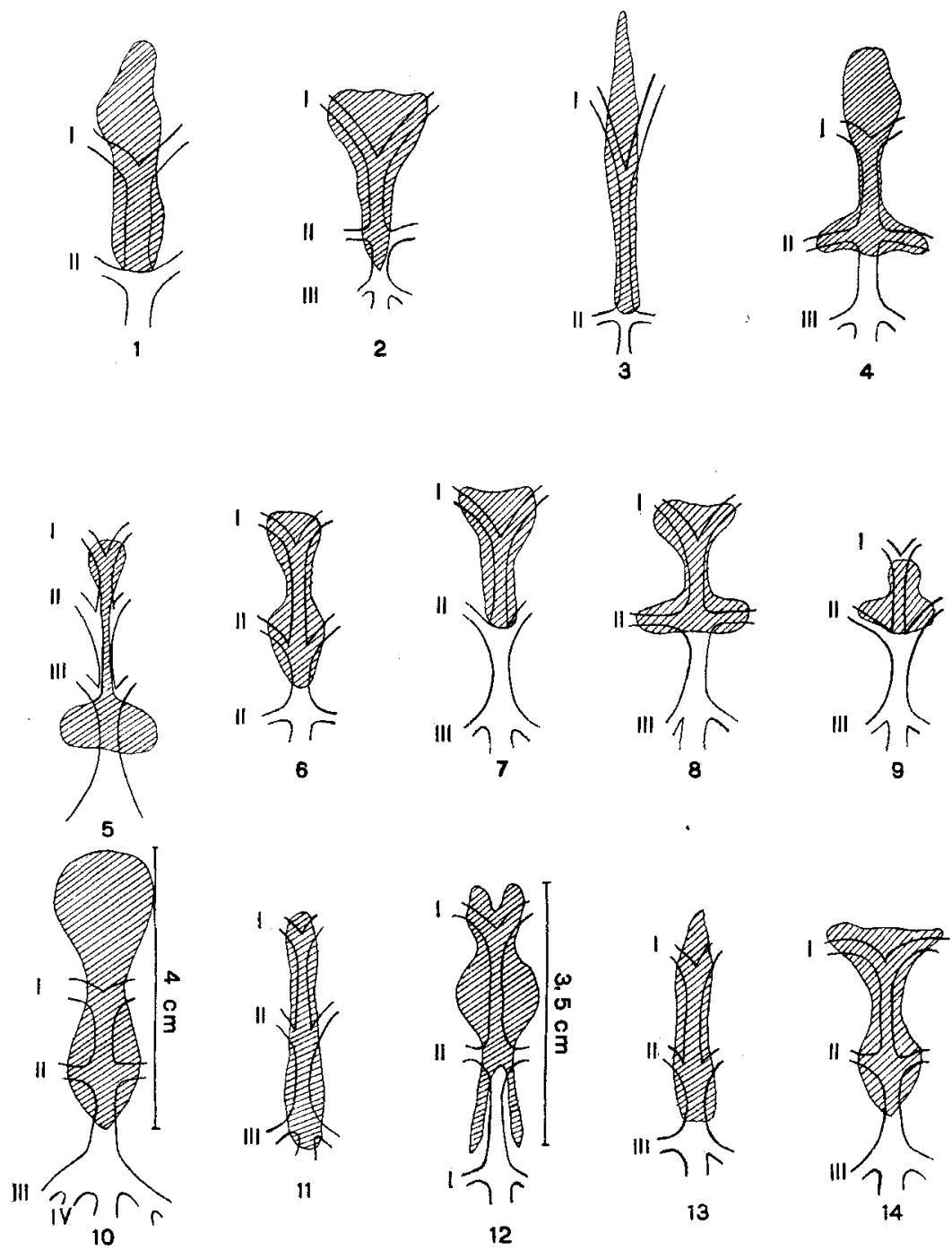

JOURNAL OF MORPHOLOGY, VOL, 21, NO. 4 


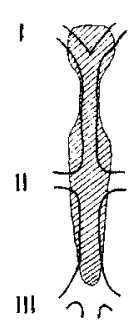

15

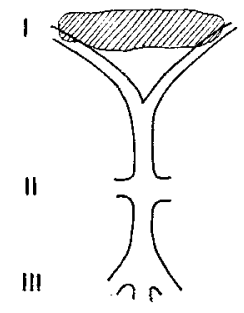

16

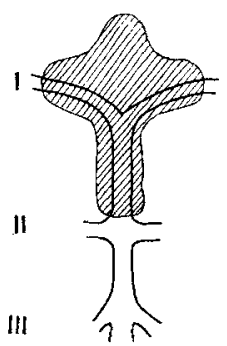

17

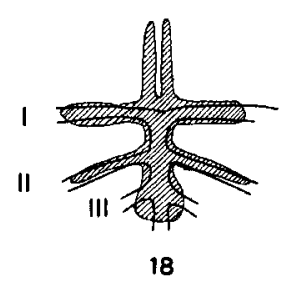

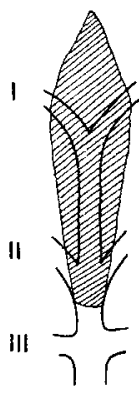

9

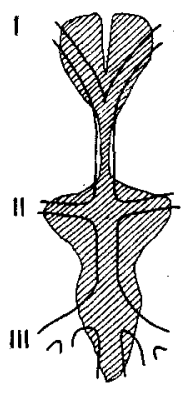

20

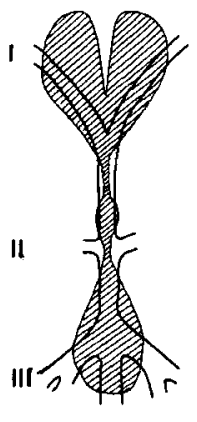

21

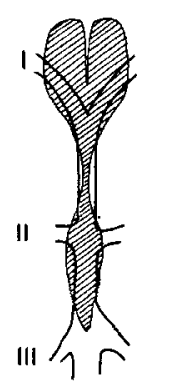

23

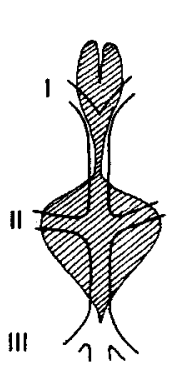

24
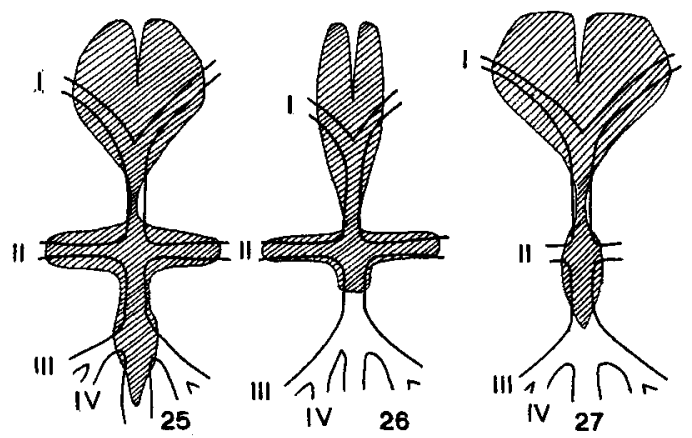

JOURNAE OF MORPHOLOGY, VOL. 21 , NO. 4 


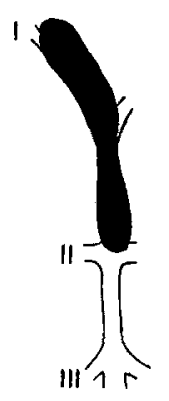

28

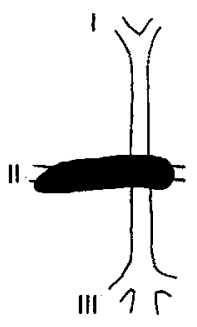

29

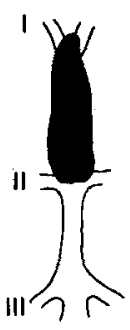

30

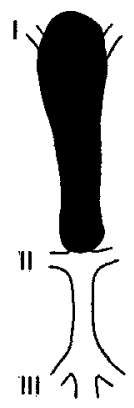

31

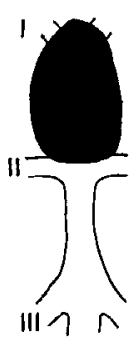

32

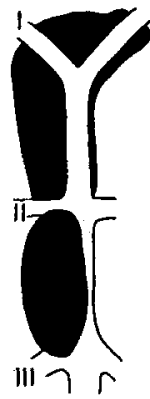

37

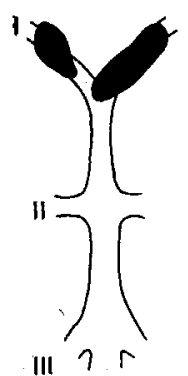

33

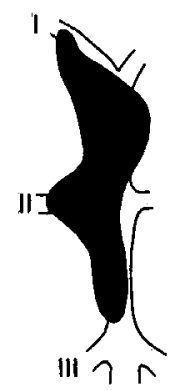

38

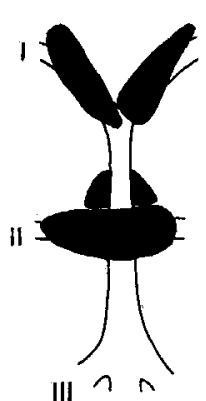

34

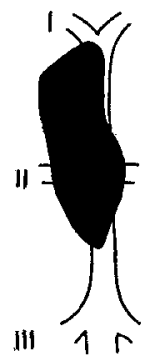

39

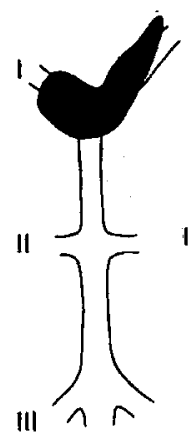

35

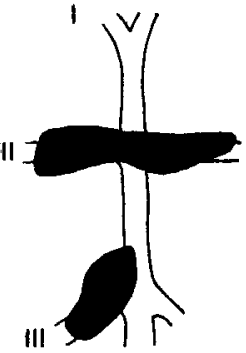

36

JOURAAL OF MORPHOLOGY, YOL. 21, No. 4 
Plates IV and V, Photographs of the histological features of the thyreoid gland in different species.

1 Brevoortia. Two follicles with their epithelial cells drawn out into spinous processes. Dia. 1: 165 .

2 Brevoortia. Two follicles, $F$ (the right one containing colloid), and a large lymph vessel, $L$, between them. The content of the vessel shows similar droplets to those sometimes seen on the surface of colloid, and believed by Anderson to contain the 'chromophobe' secretion. Dia. 1:350.

3 Brevoortia. An isolated follicle, $F$, in the most anterior portion of the thyreoid, with neighboring lymph vessels, $L$. Dia. $1: 160$. $1: 60$.

4 Brevoortia. General view of the thyreoid in the osseous capsule. Dia.

5 Brevoortia. Degenerating epithelial cells and their basal processes. $F$, Follicular lumen, $E$, Epithelium. Dia. 1: 700 .

6 Fundulus heteroclitus. Two pictures showing numerous small capillaries, $C a$, deeply buried in the epithelium, $E$, of the follicles, $F$. In the lower picture the epithelium has retracted slightly from the endothelium. $A$, ventral aorta. Dia. in $a, 1: 134 ;$ in $b, 1: 345$.

7 Siphostoma. A general view of the posterior end of the thyreoid gland. $P h$, pharynx; $A$, ventral aorta; $F$, follicles; $C a$, capillaries. Dia. $1: 34$.

8 Siphostoma. Single follicles, $F$, with their colloid forming epithelial cells, but containing no colloid. Ca, capillaries. Dia. $1: 345$.

9 Oncorhynchus. Irregular nuclei, $N$, of the epithelial cells. $E$, epithelium of a follicle viewed from the top. Dia. 1:650. 

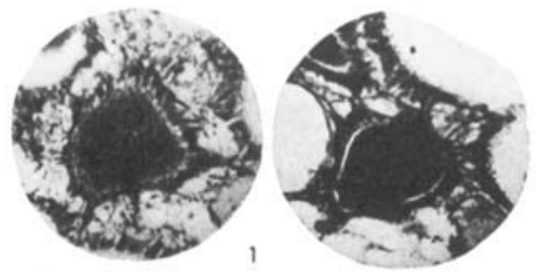

L
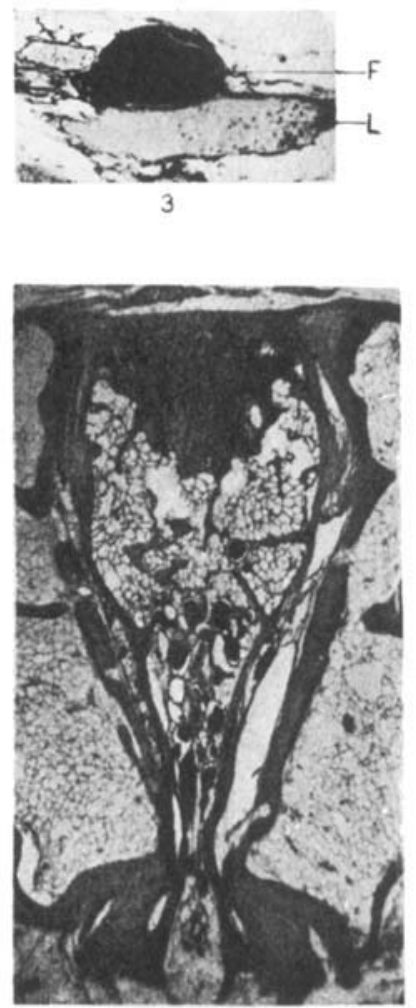

4
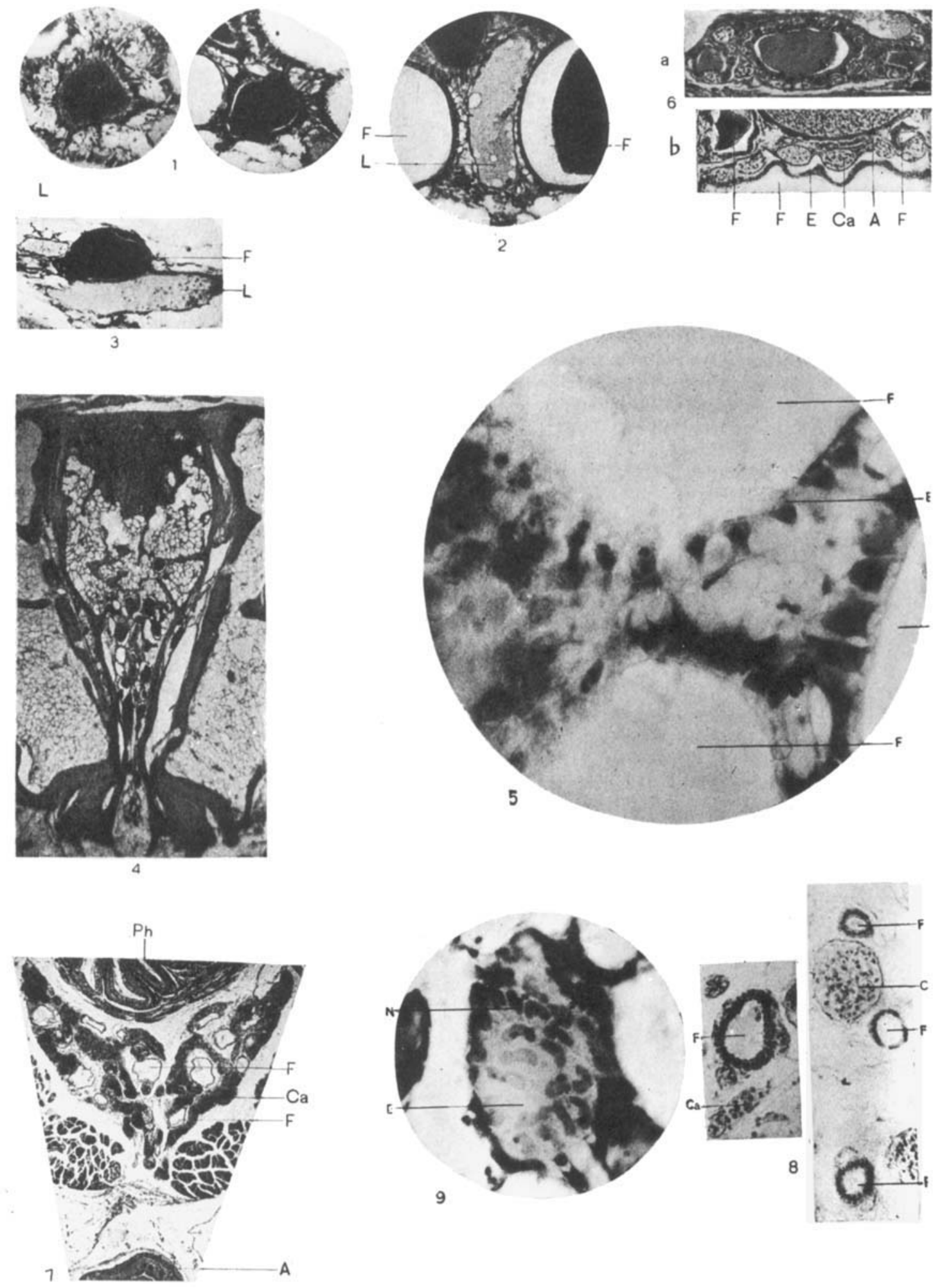

9

Jaches Photo. 
10 Salvelinus fontinalis, spec. no. III. Capillary network, $C a$, around the follicles. Note the highly columnar epithelium of the upper and the cuboidal epithelium of the two lower follicles. Dia. 1: 134.

11 Salvelinus fontinalis, spec. no. II, showing different heights of the epithelial cells in the same follicle. Dia. $1: 375$.

12 Salvelinus fontinalis, spec. no. II. Distribution of the thy reoid elements and their capillaries, $\mathrm{Ca}$, in the connective and fatty tissue network. Dia. 1:64.

13 Salvelinus fontinalis, spec. no. III. Much swollen colloid forming cells, $\mathrm{Coz}$, which have been cast off from the follicular wall into the colloid, Co. $E$, epithelium; $N$, nucleus; $V$, vesicles in the colloidal substance. Dia. 1: 650.

14 Oncorhynchus. A general view of the thyreoid gland between the first and second branchial arteries. $P h$, epithelial floor of the pharynx; $F$, follicles surrounding the copula; $A$, ventral Aorta. Dia. 1: 60 .

15 Anguilla. A duct, $D$, connecting a small, $f$, and a large thyreoid follicle, $F$. Dia. 1: 165 .

16 Anguilla. This photograph shows a complex of follicles which, on tracing through the series, are found to connect with the follicle, $F$, on the right side of the illustration. Dia. $1: 170$.

17 Cynoscion. A general view of the densely arranged follicles of this speeies. Co, colloid; $E$, epithelium. Dia. 1: 165 .

18 Cynoscion. 'This picture shows the ramifying lymph spaces, $L$, completely filled with the same substance as the follicles, $F$. Dia. 1: 170 .

19 Tautoga. The epithelial wall, $E$, of the follicle, $F$, is cut somewhat tangentially so that the network of anastomosing capillaries, $V a$, enclosing the follicles can be seen. Dia. 1: 145 .

20 Clupea. Much swollen colloid forming epithelial cells, Coz, in a colloid zone. Dia. $1: 170$.

21 Sarda. Showing smooth muscle bundles, $M$, invaded by thyreoid follicles. Dia. 1: 60 . 

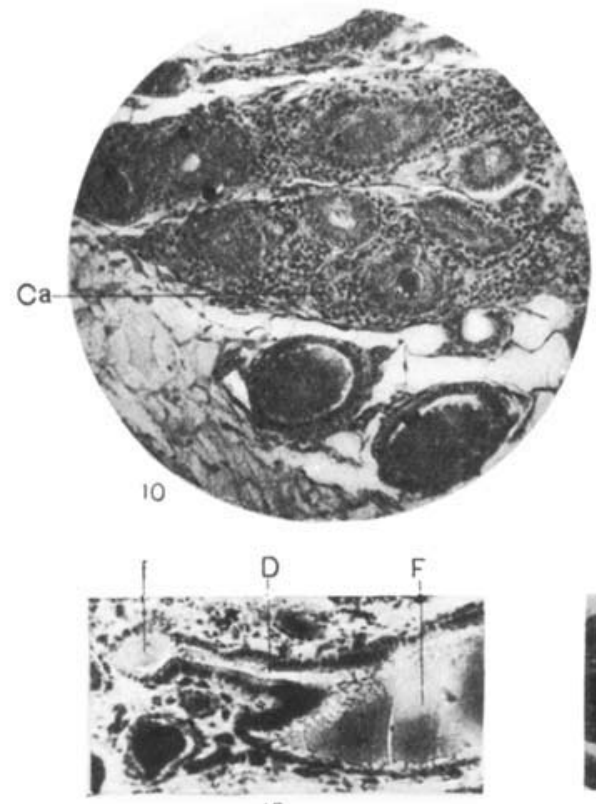

15
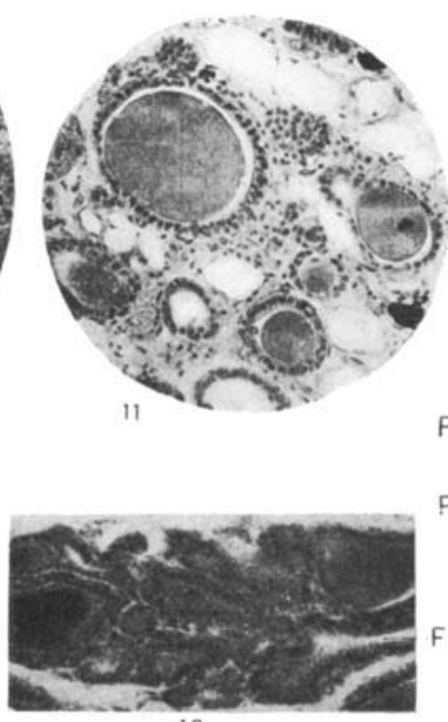

16
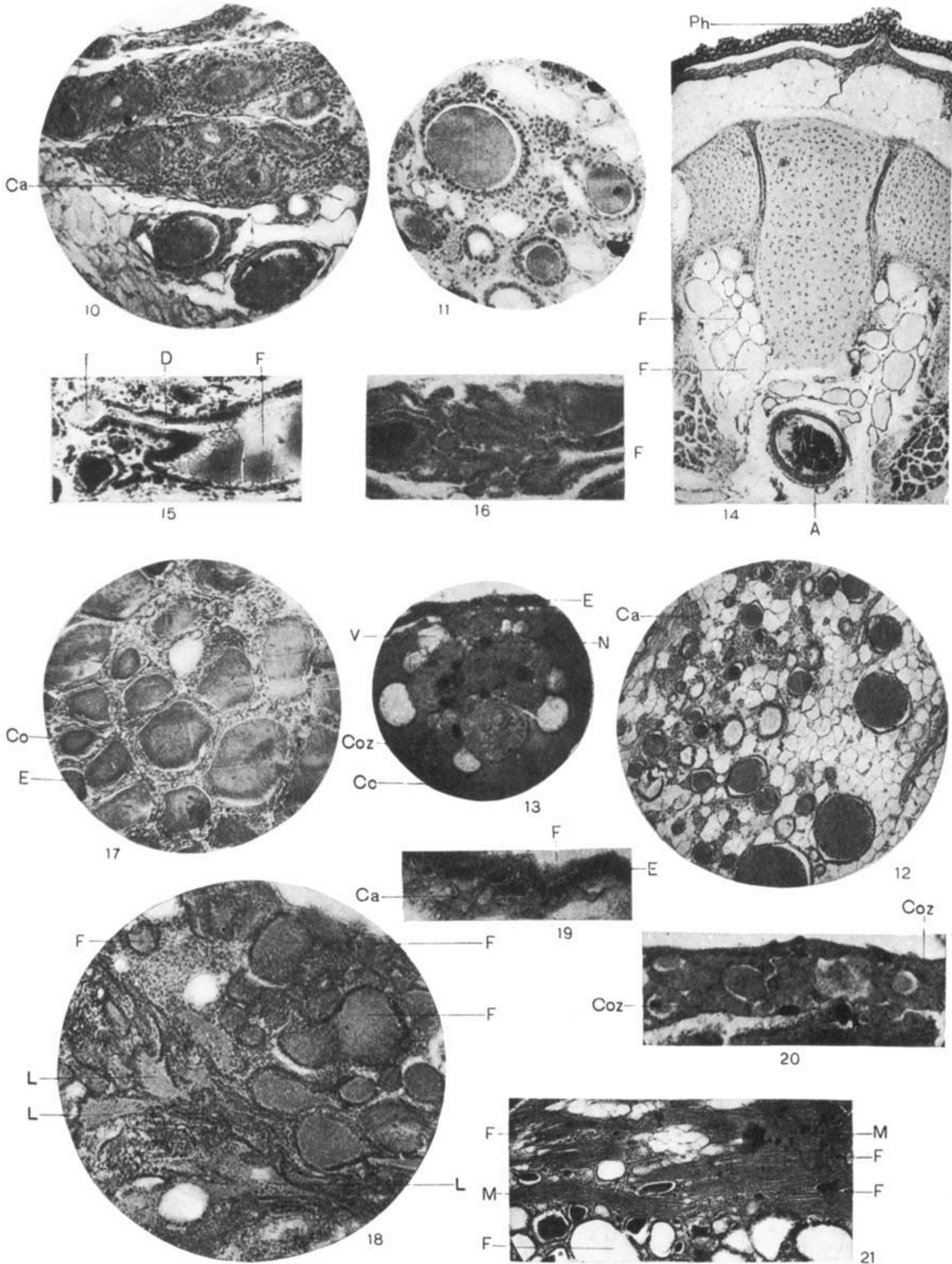

19

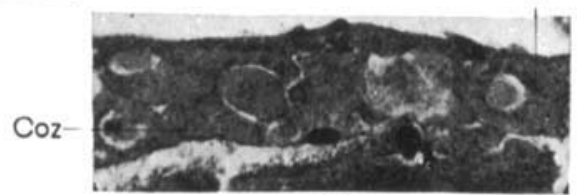

20

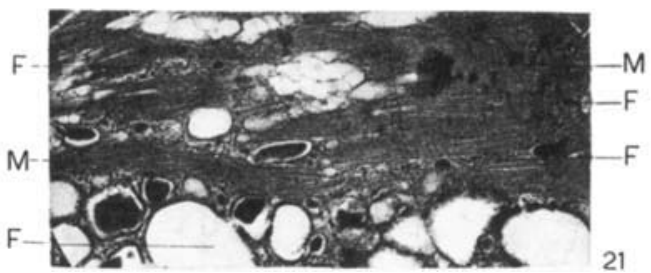

Jaches photo. 